\title{
Armed Employees and School Policy: The Issues and Perspectives of School Employees Regarding Armed Personnel in a Rural High School Setting
}

\author{
Mark A. Ratliff \\ Cedarville University
}

Follow this and additional works at: http://digitalcommons.cedarville.edu/education theses

Part of the Elementary and Middle and Secondary Education Administration Commons

\section{Recommended Citation}

Ratliff, Mark A., "Armed Employees and School Policy: The Issues and Perspectives of School Employees Regarding Armed Personnel in a Rural High School Setting" (2014). Master of Education Research Theses. 66.

http://digitalcommons.cedarville.edu/education_theses/66 
ARMED EMPLOYEES \& SCHOOL POLICY

\title{
ARMED EMPLOYEES \& SCHOOL POLICY - THE ISSUES \& PERSPECTIVES OF SCHOOL EMPLOYEES REGARDING ARMED PERSONNEL IN A RURAL HIGH SCHOOL SETTING
}

\author{
A project submitted in partial fulfillment \\ of the requirements for the degree of \\ Masters of Education
}

By

\author{
MARK ANDREW RATLIFF \\ B.A. Integrated Math Education, Cedarville University, 2009
}

2014

Cedarville University 
ARMED EMPLOYEES \& SCHOOL POLICY

\author{
ABSTRACT \\ This mixed-methods study examines the perceptions of classified and certified staff \\ members at a rural, Southwestern Ohio high school and was based on results from a 27-item \\ questionnaire. The study covered three main topics: (1) perceptions of safety, (2) perceptions of \\ armed employees, and (3) views on what procedures and limitations should be in place if a \\ school were to adopt an armed employee policy. With results similar to previous nationwide \\ surveys, $94.4 \%$ of participants believed their school is a safe place to work, however only $66.7 \%$ \\ believed their school has sufficient procedures in place should a school shooting occur. Also the \\ results indicated that $38.8 \%$ of participants would be willing to carry a concealed weapon on \\ school grounds, $30.6 \%$ would not be willing to carry a concealed weapon, and $30.6 \%$ were \\ unsure. While many of the participants believed that there is a need to fight back, they also \\ raised concerns regarding teachers carrying concealed weapons such as: weapon security, \\ training, and mental health stability. The results showed a significant difference between the \\ perceptions of certified and classified staff in the following areas: (1) the sufficiency of current \\ procedures; (2) having multiple teachers carry concealed weapons; and, (3) having multiple \\ administrators carry concealed weapons. The research also indicated the need for schools to \\ critically examine, discuss, and practice the procedures that are already in place in order to \\ ensure that the current procedures are sufficient should an active shooting occur.
}




\section{TABLE OF CONTENTS}

CHAPTER I: Introduction........................................................

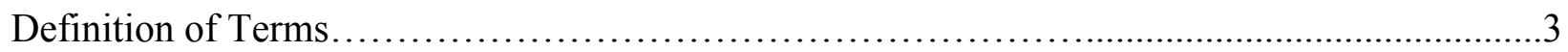

Statement of the Problem...........................................................

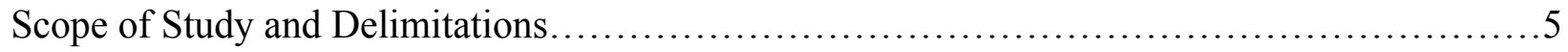

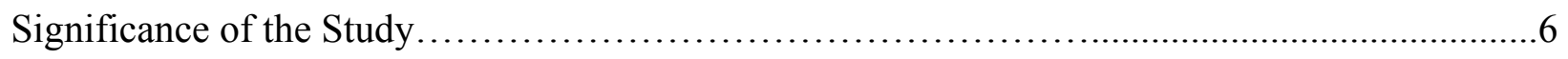

Methods of Procedure ....................................................................

CHAPTER II: Plenary Literature Review.........................................................

A Learning Experience: Previous School Shootings and Preventative Efforts.................11

New Threats and New Security Measures........................................... 17

The Armed-Teacher Debate....................................................... 19

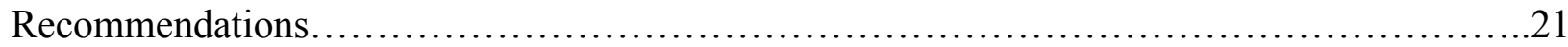

CHAPTER III: Methodology.....................................................24

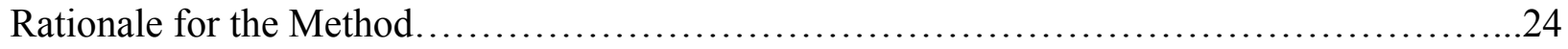

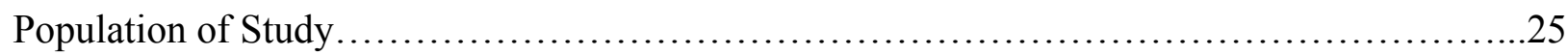

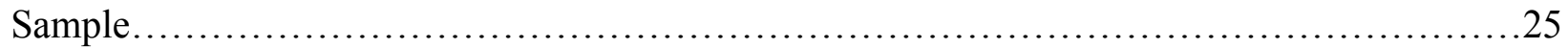

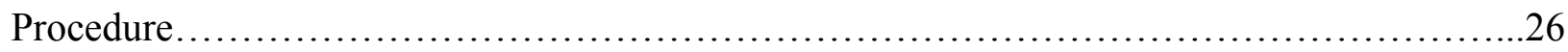

CHAPTER IV: Quantitative and Qualitative Findings.................................29

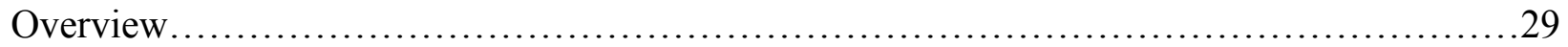

Perceptions of Safety: Data, Analysis, and Conclusions................................. 30

Perceptions of Armed Employees: Data, Analysis, and Conclusions......................... 32

Policy Considerations for Armed Employees...........................................36

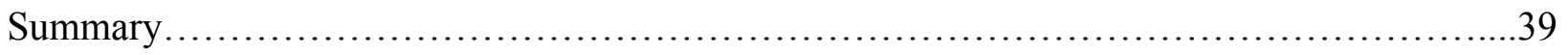


CHAPTER V: Discussion and Implications....................................... 40

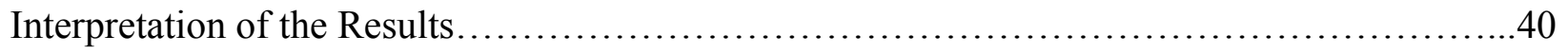

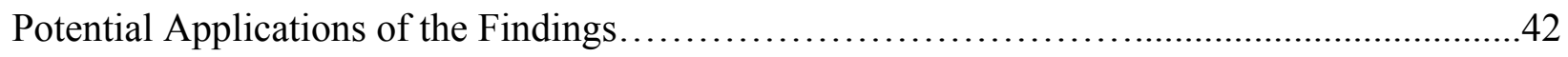

Relation of the Results to Literature.............................................44

Biblical Integration.......................................................... 45

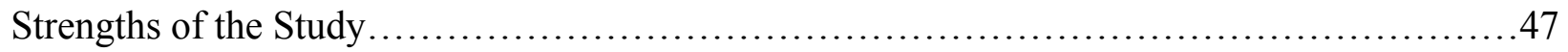

Limitations of the Study ..................................................... 48

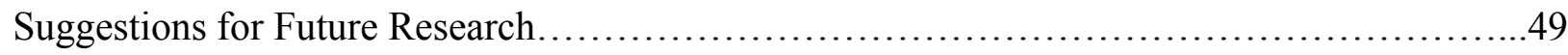

REFERENCES............................................................ 51

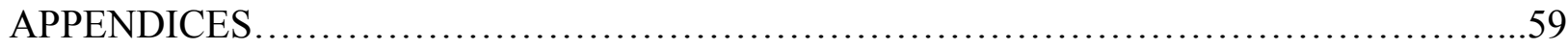

APPENDIX A: Questionnaire............................................59

APPENDIX B: Randomized Hypothesis Testing Results ........................64 


\section{List of Figures}

Figure

Page

1. Classified v. Certified perceptions of current procedures to stop an active shooter........31

2. Classified v. Certified perceptions of multiple, armed teachers........................33

3. Classified v. Certified perceptions of multiple, armed administrators..................34 
ARMED EMPLOYEES \& SCHOOL POLICY

\section{Chapter I: Introduction}

With the highly publicized shootings of 2012 the issue of gun control has been brought back into the forefront. While we have previously witnessed mass shootings at movie theatres, malls, and churches both sides of the political continuum agree that after the events in Newtown, Connecticut in December of 2012 we may have finally reached our tipping point. Many believe that something must be done- - but what exactly is the long-sought solution toward preventing these tragedies?

While it appears that the number of these violent acts have only increased, in the past 20 years the number of school-associated violent deaths have actually been on a steady decline (Robers, Zhang, \& Truman, 2012). Even though the statistics say otherwise, it seems like we are seeing more and more violent acts. One possible reason is that we live in such a media-saturated culture where news can travel from coast to coast with the click of a mouse- - even 15 years ago the Internet was just in the process of becoming mainstream. Reporters and other members of the media tend to be in such a hurry to be the first to report a story that they relay inaccurate information or they simply rely on popular social media outlets to gather their information-it is nearly impossible to escape the massive amount of information that is constantly being transmitted (Wigley \& Fontenot, 2010). Second, while the overall number of violent acts has decreased we have had two significant clusters of mass killings over short periods of time in the past 20 years. The first of which occurred between October 1997-May 1999 (Kleck, 2009), and the second being the more recent events from February 2012-December 2012. When violent acts are committed and in particular mass shootings, there can appear to be a game of "copy-catting" or "one-upmanship" in which each successive killer tries to top the previous one (Ferguson, Coulson, \& Barnett, 2011; Maxwell, 2007). 
ARMED EMPLOYEES \& SCHOOL POLICY

While there have been many attempts to profile these shooters and pinpoint an explanation, so far we have largely fallen short in our attempts (Ferguson et al., 2011). Mass shooters are not a new phenomenon - although after the shootings in Aurora, Colorado and Newtown, Connecticut in 2012 it appears as if they are becoming more successful and prevalent. In the weeks following the shooting at Sandy Hook Elementary School there were many suggested solutions, most of which had been highly politicized. Gun-control advocates were calling for tougher gun control restrictions while others called for armed guards at every school (Ripley, 2013). It was even proposed that more schools should allow administrators and/or teachers to carry concealed weapons on school property. Harrold Independent School District in Harrold, Texas was one of the first districts to adopt this approach. The district allows teachers who have a valid state concealed carry license to carry a firearm on school grounds. The teachers must be board approved to do so, use ammunition that limits any ricochet effects, and they must be provided additional training on how to handle crisis situations (Harrold Independent School District, 2013). The Butler County (Ohio) Sheriff also had a unique proposal - hire armed, retired police officers to serve as substitute teachers/armed guards in schools. The substitutes could provide protection and/or make arrests while the mere possibility of their presence could serve as a deterrent to a school shooter (Pack, 2013).

Of course, when you have weapons on a school campus there are always serious risks involved. Some who oppose having armed employees in schools say that it can send the wrong message to students or it opens up the risk for accidental shootings. Previous research has suggested that among parents, arming teachers is one of the least favorable suggestions toward decreasing school violence (Bliss, Emshoff, Buck, \& Cook, 2006). 
ARMED EMPLOYEES \& SCHOOL POLICY

After the horrific events at Sandy Hook in December of 2012 there has been a renewed focus toward finding a way to make sure every child is safe while they are at school. As important as it is to protect all students while at school it is also necessary to examine all the issues and risks involved when developing school policy, especially when it comes to school safety.

\section{Definition of Terms}

Armed Employees: Any authorized school employee that has been board approved and has a state concealed carry license to carry a weapon on a school campus, and therefore chooses to carry a concealed weapon on campus (Harrold Independent School District. 2013).

Assault weapons: Military style automatic or semiautomatic firearms (Koper \& Roth, 2002).

$C C W$ : Carry a concealed weapon (Dewine, 2013).

Certified Employee: A school staff member who holds a teaching or supervisory certificate for the position in which they are employed (i.e. teachers, administrators, librarians).

Classified Employee: A school staff member who does not hold a professional education certificate or is employed in a position that does not require such a certificate (i.e. cafeteria workers, custodians, secretaries).

Cyber bullying: instances that include but are not limited to: posting hurtful information about someone else on the internet; purposefully sharing private information about someone else on the internet; harassment via instant messaging, text messaging, or email; purposefully excluding another online (Robers, Kemp, \& Truman, 2013).

Gun control: Any efforts to restrict or regulate the sale or purchase of firearms (Kleck, 2009). 
ARMED EMPLOYEES \& SCHOOL POLICY

Mass shootings: Shootings in which there are four or more victims either killed or nonfatally wounded (Kleck, 2009).

SRO: School Resource Officer (Weiler \& Cray, 2011)

Violent acts: Rape, sexual battery other than rape, physical attacks or fights with or without a weapon, threats of physical attack with or without a weapon, and robbery with or without a weapon (Robers et al., 2012).

Zero tolerance: polices enacted by schools in which students were automatically suspended or expelled for infractions like weapons possession, disruption, drugs, or gang activity. These policies were passed along with the Gun Free Schools Act of 1994 as sweeping attempt to take back control of the schools and provide districts with the power to increase social control in order to prevent violence (Mongan \& Walker, 2012)

\section{Statement of the Problem}

With the increase of mass shootings that we were faced with in public places and especially at schools during 2012 there has been a new push toward finding a way to curb the violence. Our schools are meant to be a safe haven for students and a place for them to grow, learn, and most importantly feel free from danger. Unfortunately this has not always been the case as demonstrated by the atrocities at Columbine High School in 1999, Virginia Tech in 2007, Sandy Hook Elementary in 2012 and numerous other incidents in between. Previous research has suggested that in order to prevent school shootings it is important that schools focus on developing relationships and making sure students feel connected to their school, however this is something that can take years to develop. (Daniels et al., 2007; Daniels et al., 2010; Bliss et al., 2006).

Being able to respond to any sign of danger in an effective and efficient manner is critical 
toward protecting both students and employees. Traditionally schools would call the local police department with any signs of danger, however with some rural jurisdictions having long response times, it might be too late before help could arrive (Harrold Independent School District, 2013). One possible solution has been hiring armed guards for every school, however in today's economy that just is not a possibility for many budget-conscious districts. So what options are left? How are schools to respond to imminent danger when lives are at stake? Many politicians, parents, and leaders have voiced their opinions on the issue but what about the teachers and other staff members who work in schools on a daily basis? In order to develop an effective school policy it is important to examine all possible solutions and possible problem areas. For this project the goal is to find out the perceptions that school employees in a rural high school setting have toward some of the proposed solutions that have previously been mentioned. The target audience will be the classified and certified staff at a rural high school in Southwest Ohio.

\section{Scope of the Study and Delimitations}

The school being studied for this project has a student population of approximately 600 in grades $9-12$. Roughly $14 \%$ of students at this school are living in poverty and $96 \%$ of the students are white. For this project the perceptions of school employees in regards to having armed personnel as a means to stop an active shooter in this particular setting is being studied. While there has been much research conducted on what schools can do to proactively prevent school shootings, this study was conducted in order to gather information regarding school employees' perceptions and comfort levels with arming workers as a reactive way to stop an active shooter. Also, as part of this study some hypothetical situations in which this school allowed certain employees to carry concealed weapons on campus were reviewed-What precautions would need to be taken? What policy issues would need to be considered? Since 
ARMED EMPLOYEES \& SCHOOL POLICY

only one school was used in this study, the results could not be generalized to other high schools. However the results could be used as a starting point for schools with similar demographics that are considering adopting an armed employee policy.

This project focused solely on school employees' perceptions of allowing school personnel to carry a concealed weapon as a means to stop an active shooter. Student perceptions were not included as a part of this study, although it would be an interesting topic for further study. Also, it is important to note that while employees were asked their opinions on having armed personnel in the school, participants were asked to take the perspective of how they would develop school policy if the school board approved certain employees to carry concealed weapons on campus.

\section{Significance of the Study}

While gun control is currently one of the more publicized topics in the media, over the past 20 years we have witnessed an alarming number of mass school shootings. Many schools have implemented security procedures such as metal detectors, lock-down drills, controlled access to school buildings, and anti-bullying campaigns, however schools can have many safety procedures in place yet still be susceptible to mass shootings (“After Newtown”, 2013). If all preventative measures have failed how can schools safely and effectively respond to an active shooter situation? While the idea of arming school employees has been highly debated in recent months it is important that we examine and evaluate all avenues in order to make our schools as safe as possible. This study will help bring to light the perceptions of certified and classified staff in regards to certain policy issues that may arise if a school, in particular a rural high school, were to adopt an armed employee policy. Also this study will examine other possible solutions for reacting to an active shooter. It is important to make sure that all the possible benefits are 
ARMED EMPLOYEES \& SCHOOL POLICY

weighed against any potential liabilities before enacting new policy. This study will help expose any potential problems and recommend solutions for enacting (or not enacting) a safe and appropriate armed employee policy.

\section{Methods of Procedure}

An examination of the current literature was conducted on school shootings and their possible causes, possible solutions, and student/parent perspectives. Upon completing the literature review, it was discovered that while many students, parents, and administrators have given their perspectives on school shootings/violence, there has not been much research conducted on classified and certified employees' perspectives for preventing the next school tragedy. Therefore in order to gather the largest amount of information in the most time-efficient manner a mixed questionnaire was constructed and sent out for all school employees at the sample school to complete. The questionnaire contained quantitative questions using a rating scale for each employee's sense of safety (agreement) and also possible solutions for reducing school violence (approval). Also included in the questionnaire were open-ended questions relating specifically to the issue of armed employees as a possible solution. It was also made evident that while previous research has made it clear that building positive relationships and increasing student connectivity are key components toward decreasing school violence, the purpose of this research was to discover the perspectives of employees in regards to responding to a school shooting that was already in progress. (Daniels et al., 2007; Daniels et al., 2010; Bliss et al., 2006).

In order to encourage participation, those who completed the questionnaire were given the opportunity to be placed into a drawing for one of two \$20 gift cards to a popular chain restaurant. Although each participant placed their name into an envelope for the drawing, they 
were also asked to place their questionnaires into a separate envelope so that their name could not be linked back to their responses. Lastly, participants were also asked to complete the survey as honestly and as completely as possible.

After all responses were collected, a quantitative analysis on the rating scale questions was conducted and three levels of coding were used for the qualitative questions (open, axial, \& selective). By combining both quantitative and qualitative methods data was gathered and analyze rather quickly while still leaving room for the participants to express their opinions via open-ended questions. 
ARMED EMPLOYEES \& SCHOOL POLICY

\section{Chapter II: Plenary Literature Review}

With some of the more recent mass shootings the issue of gun control has been brought back into the forefront. Gun-control advocates argued that more guns would mean more problems while others contended more guns are necessary for better protection (Ripley, 2013). Regardless of one's stance on the issue, gun violence has become a problem among our children in the United States when compared to other nations - children in the United States are 13 times more likely to be killed in a gun homicide that Finland, France, or New Zealand (JeeHae, 2013). One way educators have tried to cut down on the number of gun deaths has been to try and reduce the amount of accidental shootings by teaching gun safety at the elementary level. Ten percent $(10 \%)$ of elementary teachers surveyed in a 2005 study said that they were teaching firearm safety at the time (Price, Murnan, \& Thompson, 2005). In a later survey, $62 \%$ of elementary teachers said that they would approve of some form of gun safety educationalthough the majority of those who approved thought that the person who does the training should be trained police or military personnel (Obeng, 2010). Only 45.2\% of parents believe that their children should receive gun safety education in school (Howard, 2005).

While efforts have been made by educators inside of school to reduce the amount of accidental shootings, policy-makers have also played a role in trying to prevent those guns from entering our schools. As a reaction to the increased amount of gun homicides nationwide during the 1980s and 1990s, many cities introduced handgun bans during that time (Nieto, 2011). Also, in 1994 the Federal Assault Weapons Ban was approved by Congress and signed into law by then President Bill Clinton (Koper \& Roth, 2002). At first the number of available assault weapons decreased causing demand and black market prices to rise. However, with the increased demand came increased production (albeit illegal) and after just a few years the 
ARMED EMPLOYEES \& SCHOOL POLICY

number of alternative assault weapons on the streets was higher than before the ban was put into place (Koper \& Roth, 2002). Similarly, Chicago had a handgun ban in place from 1983-2008; however during this time the percentage of murders committed by handguns in the city increased $40 \%$ (Nieto, 2011). Conversely, Australia is an example of a country where the number of firearm homicides has been steadily declining since the National Firearms Agreement of 1996 was put into place (Hirsh, 2013). However, Hirsh (2013) also points out that Australia does not have a constitutionally protected right to keep and bear arms like the United States.

Schools were not immune toward the anti-gun movement, and as a result of the increase in gun violence during the 1980s and 1990s, many states and school districts introduced the "gun free zone" and "zero-tolerance" policies for schools. Coinciding with the Federal Assault Weapons Ban in 1994, the Gun Free Schools Act was passed the same year (Mongan \& Walker, 2012). Critics claim that the zero tolerance policies that emerged from the law have caused numerous examples of overreacting. One author made the point that schools "shouldn't be expelling 5-year-olds for bringing squirt guns to school” (Mongan \& Walker, 2012). Also, following the December 2012 shootings at Sandy Hook Elementary School some were also calling for a renewal of the Federal Assault Weapons Ban that had expired in 2004 (Shah, 2013c). However research suggests that banning assault weapons or limiting magazine capacity would do nothing to reduce the amount of fatalities in school shootings since typically the shooters use pistols (60\%) and carry multiple weapons along with multiple magazines (Kleck, 2009; JeeHae, 2013).

Despite these new statutes in place, in the 2005-2006 school year $24 \%$ of public schools took serious action against students for weapon possession or use (Gastic, 2010). The most common offenders who brought weapons into school were $8^{\text {th }}$ or $9^{\text {th }}$ graders who experts believe 
ARMED EMPLOYEES \& SCHOOL POLICY

brought the weapons into school for a variety of reasons: a fascination of weapons; trying to gain social status; for protection; or to physically harm another student (Fritz \& Radka, 2010). Even though the number of students bringing weapons to school has not decreased as a result of legislation, the number of school associated violent deaths has been on a steady decline over the past 20 years (Robers et al., 2012).

Perhaps what concerns educators, parents, and lawmakers alike is that even though the number of school associated violent deaths has been on a decline, the number of targeted school shootings has increased every decade since the 1960s (Warnick, Johnson, \& Rocha, 2010). Many experts have tried to identify the causes of school shootings and even attempt to create a shooter profile, however trying to identify a threat is much easier said than done (Kanan, 2010).

\section{A Learning Experience: Previous School Shootings and Preventative Efforts}

Of all the possible explanations for why a school shooting occurs, perhaps the most discussed issue is bullying. In a 2013 analysis of the 593 school shootings that had occurred in the United States from the 1760 s to 2013 , the author found that $87 \%$ of the school shooters were bullied in some form or another (JeeHae, 2013). This is not an isolated issue - roughly $70 \%$ of K-12 students in the United States reported being bullied at some point (Beaty \& Alexeyev, 2008). Approximately $64.5 \%$ of students reported being bullied at school (Robers, Kemp, \& Truman, 2013), and when bullying does occur teachers are less likely to see it — it occurs mostly in the halls and at lunch (Beaty \& Alexeyev, 2008). Also, a new type of bullying that many schools are dealing with is "cyber bullying". Cyber bullying occurs $11 \%$ more often with females than males, regardless it has become such a problem that it has forced many school districts and the courts to revise and create policies in order to protect students (Robers et al., 2013). School administrators have taken a keen interest in reducing bullying because when it 
ARMED EMPLOYEES \& SCHOOL POLICY

occurs the school could be held liable (DeAngelis, Brent, \& Ianni, 2011). Bullying is a tenant of student-to-student marginalization - the competitive school environment can further marginalize some students and even intentionally or unintentionally ostracize those who don't fit into the culture (Thompson \& Kyle, 2005). This marginalization is also a common characteristic of school shooters according to Thompson \& Kyle (2005).

Other than being bullied there are very few other commonalities that school shooters share (JeeHae, 2013). JeeHae (2013) reported that 75\% of school shooters were white, $66 \%$ had never been in trouble before, $12 \%$ had some sort of drug involvement, and the shooters all came from a variety of different family structures, socioeconomic groups, and backgrounds. Also according to JeeHae (2013), school shootings take place at a variety of different type of schools - from urban, to suburban, and even rural. However, statistics point to a larger number of school shootings occurring at larger urban or suburban schools with mixed race populations (De Apodaca et al., 2012). Because of the wide array of backgrounds school shooters can come from, prevention efforts should not try to find a profile but rather should focus on the behaviors and communications that take place (JeeHae, 2013). One of the common behaviors that school shooters tend to possess is that their attacks are not impulsive, but rather planned and calculated (Kanan, 2010). School shooters tend to be narcissistic, have a lack of empathy \& conscience, and display sadistic behavior (Langman, 2009). Perhaps the most condemning characteristic for schools however, is that roughly $60 \%$ of the time the shooter(s) had told someone else about their plans (Daniels et al., 2010; Fritz \& Radka, 2010; JeeHae, 2013; Kanan, 2010). When this occurs, school shooters will not only tell someone else about their plans but they will usually be very specific and then obtain weapons afterward (Department of Justice, 2002). 
ARMED EMPLOYEES \& SCHOOL POLICY

In light of the fact that roughly 3 in 5 school shooters will tell someone about their intentions beforehand, it is important for schools to create a caring, sharing climate (Department of Justice, 2012; Fritz \& Radka, 2010). Previous research has suggested that students are often hesitant to report friends who they know might have a gun on school grounds (Haselswerdt \& Lenhardt, 2003). This shows the need that students along with teachers must be trained to report possible threats, even if it is from a friend (Swezey \& Thorp, 2010). Bystanders to bullying, threats, and/or physical violence are not neutral observers - they influence violence for good or bad. This is why it is important to encourage students to act proactively (Wilson-Simmons, Dash, Tehranifar, O’Donnell, \& Stueve, 2006). Preventing bullying is also critical because psychological and emotional violence leads to physical violence (Haselswerdt \& Lenhardt, 2003). Opponents argue that talking about these type of things with students may create an unnecessary anxiety within the student body, however the author notes that it is important not to fear that students will feel insecure as a result of these prevention plans being talked about (Ericksen, 2013).

While collective school interventions have been proven to positively reduce the amount of school violence (Wilson-Simmons et al., 2006), the creation of a trusting, sharing environment within a school has to overcome some initial barriers. Students are often hesitant in reporting possible threats because of the "code of silence" among themselves - students don't want to be labeled as a "snitch" (Haselswerdt \& Lenhardt, 2003). Another reason students may be hesitant in reporting threats is because there is a disconnect between the students and adults in schoolsstudents don't feel respected and that their anonymity will be protected when reporting a threat (Haselswerdt \& Lenhardt, 2003; "What's Working," 2013). One way that schools have tried to 
ARMED EMPLOYEES \& SCHOOL POLICY

make students feel more secure about reporting threats was through the creation of 911 and webbased anonymous tip lines (Garza, 2002).

Schools have also tried to bridge the gap between students and adults by hiring School Resources Officers (SROs) to help build relationships with students (Cray \& Weiler, 2011). The first SROs appeared in Flint, Michigan in 1953, however, the number of SROs dramatically increased in the 1990s as a result of the increased number of school shootings and the implementation of gun free zones and zero tolerance policies (Weiler \& Cray, 2011). A 2005 study showed that urban students generally support having security officers in the schools, however students have neutral opinions on several other security measures such as security cameras and metal detectors (Brown, 2005). As of 2011, roughly $35 \%$ of high schools across the United States employed an SRO (Weiler \& Cray, 2011). Another purpose of SROs is to create an intermediary for the schools and law enforcement (Cray \& Weiler, 2011). This intermediary serves to benefit both the school and the police department: the school benefits in this relationship since the school environment is directly impacted by the community environment (Johnson, Burke, \& Gielen, 2011); law enforcement benefits from this relationship because schools are often manifestations of larger community issues (Weiler \& Cray, 2011). In studying averted school shootings, some characteristics that those schools had in common were: a strong connection between the schools and local law enforcement; interventions occurred at the family, neighborhood, and school levels; and communication along with relationships were key in preventing a tragedy (Daniels et al., 2007; Daniels et al., 2010). Parental and community involvement can also help to decrease fears that students may have in regards to school violence (Hong \& Eamon, 2012) 
ARMED EMPLOYEES \& SCHOOL POLICY

Another step that some schools have taken to reduce violence and create a safer environment came through the use of metal detectors. Critics argue that schools should be hesitant in acquiring metal detectors because they can negatively impact the school environment and increased security can actually escalate violence (Johnson et al., 2011). Since there has been no real data to support the use of metal detectors in schools (Fritz \& Radka, 2010; Hankin, Hertz, \& Simon, 2011), others believe that instruction on violence prevention may be more beneficial and more cost effective than metal detectors (Hankin et al., 2011). As stated earlier, in the 2005 -2006 school year $24 \%$ of public schools took serious action against students for weapon possession or use (Gastic, 2010). Gastic (2010) also reports that of the weapons that were found, staff discovered $38 \%, 22 \%$ were reported by students, and metal detectors only detected $11 \%$. As of the 2009-2010 school year metal detectors were only being used in $1.4 \%$ of schools in the United States ("What's Working," 2013).

The importance of creating a sharing, trusting climate is critical because students shouldn't be worrying about physical safety while at school (Fritz \& Radka, 2010). However, in addition to schools taking proactive measures to prevent school shootings, it is also important for schools to have a crisis plan in place should a dangerous situation ever occur (Cowan \& Rossen, 2013; Estep, 2013; Razi \& DeChillo, 2005; Zubrzycki \& Shah, 2013). Many schools have had crisis plans in place for decades, however it wasn't until the 1990s that schools were now forced to add "active shooter" or "lockdown" drills to the more common fire and tornado drills (Cowan \& Rossen, 2013). In order for a school to develop a crisis plan, several authors recommend the following steps: (1) form a committee or collaborative team; (2) define the crisis, understand the threats; (3) determine goals and create the plan; (4) train and retrain those involved; (5) implement the plan; and (6) assess and revisit the plan annually (Estep, 2013; Zubrzycki \& Shah, 
2013). School counselors should also be ready to serve as leaders in the midst of a crisis - many times counselors are looked to first during and after a crisis situation, even before the building principals (Fein, Carlisle, \& Isaacson, 2008). While many schools have these plans in place, a large number of them do not practice them out of the fear of creating anxiety in students (Razi \& DeChillo, 2005; Zubrzycki \& Shah, 2013). As stated previously, schools should not let the threat of student anxiety stand in the way of discussing and drilling for potentially dangerous situations (Ericksen, 2013). Teachers along with students must be trained and drilled what to do in these situations - It can be the difference between calm and chaos, or even life and death (Kennedy, 2007).

Another important part of a crisis plan that a school should have in place should be a plan to address the media if a crisis situation should ever occur (Razi \& DeChillo, 2005). The media has played such an important role in the shaping of public perception surrounding school shootings, most notably during and after the 1999 shootings at Columbine High School (Ferguson et al., 2011). During a crisis the media will also turn to non-official sources such as Twitter and Facebook in the initial stages in order to gather information (Wigley \& Fontenot, 2010). This demand for answers can lead to a lot of false leads. An example of a false presumption the media and some policy-makers have taken has been placing part of the blame for school shootings on violent video games-however research has shown no connection between one playing violent video games and having violent behavior (Ferguson et al., 2011). Also, many people were upset with the insensitivity of the media following the December 2012 shootings at Sandy Hook Elementary School - many news stations interviewed some of the children who were in the school at the time of the shooting. The media should respect the vulnerability of victims and witnesses in order to prevent any further trauma (Paccione- 
Dyszlewski, 2013). Perhaps the biggest problem that the media has initiated in regards to school shootings has been the issue of "Copy Catting", where others will try to replicate certain violent acts. Schools have had to deal with increased threats - especially after significant school shootings (Ferguson et al., 2011; Maxwell, 2007). When a school shooting occurs, it is typically on many news stations for a week or more. This was most notably exemplified following the Columbine shootings (Ferguson et al., 2011).

\section{New Threats and New Security Measures}

From the $1999-2000$ to the $2009-2010$ school years, schools have taken some significant measures to increase security within their buildings: the amount of schools requiring controlled access to the buildings increased from $75 \%$ to $92 \%$; schools requiring faculty identification increased from $25 \%$ to $63 \%$; the percentage of schools with security cameras increased from $19 \%$ to $61 \%$; and the amount of schools that had telephones in classrooms increased from $45 \%$ to $74 \%$ (Robers et al., 2012). Some schools have even set up their security cameras so that they can send a live feed to the local police department (Garza, 2002). Furthermore with newer wireless technology, camera feeds can be transmitted to police cruiser laptops giving police an up-to-the-minute location of possible gunmen as the police arrive on the scene (Pittman, 2010). Other security measures that have been introduced recently include: new visitor management software to check identification, sex offender lists, and possible custody issues; bullet resistant film on the glass at all entrances; panic buttons; 18 inch by 20 inch bullet proof whiteboards; and "prop and lock" doors that can buy students more time to hide in the event of an emergency (Molnar, 2013).

Sandy Hook Elementary was an example of a school that had been doing every right in regards to school security — they had controlled access to the building, practiced lockdown and 
other safety drills, and had crisis plans and relationships with the local law enforcement agencies already in place (“After Newtown,” 2013). Despite these prior security measures, the shooter was able to shoot through the glass at the front door, enter into the building, and then kill twenty $1^{\text {st }}$ grade children along with six educators in eleven minutes before taking his life. Police did not enter the building until after the shooter was already dead ("After Newtown," 2013). Nearly half of all school shootings begin and end within fifteen minutes, and the average police response time to a school shooting is roughly three minutes (JeeHae, 2013). JeeHae (2013) also points out that $27 \%$ of school shootings are over within the first five minutes.

In light of these time restraints it had been suggested by the National Rifle Association (NRA) that every school should have an armed guard (JeeHae, 2013). In 2005, there was a national debate about whether or not schools should allow school security to carry concealed weapons (Trotter, 2005). Since then, in a 2013 nationwide survey roughly $88 \%$ of teachers stated that they would be in favor of armed guards (Shah, 2013d). However, it has been estimated that this would cost U.S. schools an additional $\$ 15$ billion per year-money that many cash-strapped districts simply do not have (JeeHae, 2013). In the 2008-2009 school year districts in Texas already spent an average of $\$ 312,090$ on security (DeAngelis et al., 2011). Also, critics of hiring more security personnel argue that more officers will further encourage the school to prison pipeline (Shah, 2013a). Many schools don't have the time to wait on outside help during an emergency and they don't have the money to hire their own security — this dilemma has led many districts to come up with creative solutions in order to try and reduce the amount of victims should an active shooting occur (Pack, 2013). 
ARMED EMPLOYEES \& SCHOOL POLICY

\section{The Armed-Teacher Debate}

It has been pointed out that due to the time it takes first responders to arrive on the scene, teachers should be trained as the first responders (Ericksen, 2013). Following the events at Sandy Hook the NRA proposed that teachers be allowed to carry weapons on school grounds as a way to protect themselves and others (JeeHae, 2013). This suggestion has been met with praise from some pro-gun activists and with criticism from others (Ripley, 2013).

Proponents of allowing teachers to carry concealed weapons list a number of reasons:

teachers are first responders and can reduce the amount of victims by simply intervening quicker than police (Harrold Independent School District, 2013; Pack, 2013; Shah, 2013e); training teachers to carry concealed weapons is more cost effective than hiring an armed security guard (Buck, Yurveti, \& Drake, 2013). Some school districts have already had armed-teacher policies in place for a number of years including Harrold Independent School District in Harrold, Texas. The district has allowed teachers to carry a firearm on school grounds since 2007 as long as they have a valid state concealed carry license. Also, the teachers must be board approved, use ammunition that limits any ricochet effects, and they must be provided with continuing, additional training on how to handle crisis situations (Harrold Independent School District, 2013). Harrold's concealed handgun policy cites the necessity of the school to arm employees since the school is 30 minutes away from the nearest first responders. The Butler County (Ohio) Sheriff has also suggested a response to the timing and budget problems - hire armed, retired police officers to serve as substitute teachers/armed guards in schools. The substitutes could provide protection and/or make arrests while their presence in the schools could serve as a possible deterrent to a school shooter (Pack, 2013). 
ARMED EMPLOYEES \& SCHOOL POLICY

Opponents of allowing teachers to carry concealed weapons cite a number of reasons as well. The "weapon's effect" is one of the more popular reasons and it basically states "the more weapons there are the more aggression there will be" (JeeHae, 2013). An additional argument is that teachers need to be setting the example and it sends a bad message if teachers are allowed to carry weapons, but there are zero-tolerance policies in place for students (Frederick, 1999). JeeHae (2013) also points out that most teachers feel that they would have trouble maintaining weapon security. Studies also indicate that most administrators oppose the measure (Buck et al., 2013), and from a 2013 nationwide survey $72 \%$ of teachers said they would be unlikely to bring a gun to school even if they were allowed (Shah, 2013d). Another argument is that even if a high amount of training were involved, the brain still reacts differently under stress creating a tunnel vision that might interfere from teachers properly assessing the situation-while the teachers exchange gunfire with the shooter, stray bullets may hit other bystanders (Ripley, 2013). Liability issues for the school district are also a concern with the increased risk of accidents (Crews, Crews, \& Burton, 2013). Although it is unclear how this would translate to a high school setting, a study performed on two college campuses during the 2008 -2009 school year showed that $70 \%$ of college students oppose allowing concealed firearms on campus (Patten, Thomas, \& Wada, 2013). The more guns there are, the less sense of safety there is (Patten et al., 2013). Previous research has also suggested that parents view arming teachers as one of the least favorable suggestions toward decreasing school violence (Bliss et al., 2006). Most opponents of arming teachers would suggest that money be spent on more mental health initiatives as proactive measures, rather than increasing security (Shah, 2013b).

Currently 42 states prohibit any guns on school grounds, however a school board can approve some people to conceal and carry (Ujifusa, 2013). In 2007 an Oregon teacher filed suit 
ARMED EMPLOYEES \& SCHOOL POLICY

against the school district who employed her citing that she had the right to carry a concealed pistol on school grounds as a means of protection. However, the court ruled against her stating that she knew the school policy before signing her contract, so the school was not required to adhere to the state concealed weapon policy (Taylor, 2008).

\section{Recommendations}

In a 2013 survey, 92\% of teachers polled stated that they felt safe in school ("Survey," 2013). However of those same teachers only $69 \%$ believed that their school was safe from gun violence. The Federal Bureau of Investigation recommends that people involved in an active shooting situation "run, hide, or fight" (JeeHae, 2013). JeeHae (2013) points out that to fight back it doesn't necessarily have to involve a gun — there are self-defense workshops available that show teachers how to disarm a shooter by hiding at blind spots and then using hands, feet, elbows, and knees to remove the weapon. However, fighting back should only be used as a last resort (JeeHae, 2013). Others view fighting back from a different perspective. Wayne LaPierre of the NRA stated, "the only way to stop a bad guy with a gun, is a good guy with a gun" (Crews et al., 2013). Regardless of how one views fighting back, schools need to be prepared to react swiftly and efficiently should an emergency situation ever occur (JeeHae, 2013). A 2013 nationwide survey revealed that of the schools and teachers who participated, only $20 \%$ said that they drill on how to deal with an armed intruder (Shah, 2013d).

The lack of preparation is concerning to a number of people. During a telephone interview with the Ohio Attorney General Mike DeWine, he listed the following five points as a recommendation for schools to proactively and reactively respond to the increased number of school shootings: (1) have a plan filed with the Attorney Generals office; (2) practice the plan over and over in conjunction with local law enforcement; (3) have all staff attend a 3-4 hour 
ARMED EMPLOYEES \& SCHOOL POLICY

training session that is provided free of charge by the Attorney General's office; (4) if a school district decides to adopt an armed employee policy they should require a minimum of 200 hours of training (in concordance with the Ohio Police Officers Academy recommendation); and (5) if a school can afford it, hire an active duty police officer to serve as a school resource officer (M. DeWine, personal interview, January 14, 2014). DeWine also stressed the importance of involving the mental health community as a preventative measure, along with the necessity of making sure all staff know what to do in the event of an active shooter or other emergency situation. The Ohio Attorney General's office can send a representative to do the training on site, or there are videos available that deal with how to identify potential shooters and what to do in an active shooting situation.

Currently, Ohio Revised Code states the following in regards to armed personnel in school settings:

(D) No public or private educational institution, or superintendent of the state highway patrol shall employ a person as a special police officer, security guard, or other position in which such person goes armed while on duty, who has not received a certificate of having satisfactorily completed an approved basic peace officer training program, unless the person has completed twenty years of active duty as a peace officer. (Ohio Revised Code, 2000)

After talking with DeWine, his interpretation of this statute was that it applies only if a school plans on hiring a person for the sole purpose of security - if a school district wants allow teachers to carry concealed weapons there are currently no training requirements (other than $\mathrm{CCW}$ ) or other limitations in place. Therefore if a school wanted to hire a teacher to carry a concealed weapon, the teacher would only need to have 12 total hours of training in order to get 
the concealed carry license and be board approved to do so on school grounds (DeWine, 2013). However, as stated before this would not be the recommendation from DeWine as he would like to see a minimum of 200 hours training and would advise schools to carefully consider the risks before adopting an armed employee policy. 


\section{Chapter III: Methodology}

In this study, the research was performed using a mixed methods approach in order to maximize the amount of information collected while at the same time leaving room for participants to express themselves qualitatively. The purpose of this research was to investigate the perspectives that both classified and certified staff members of a rural high school have toward reacting to an active school shooter. To gather the data, every staff member at the participating high school was given a mixed questionnaire with 18 closed-ended questions and 9 open-ended questions related to their perceptions of safety and possible interventions at their school. The closed ended questions were then analyzed for all participants as a whole and then separately in order to see if there were any statistically significant differences between classified \& certified staff, along with male and female teachers. The open-ended questions were coded using a three-tiered, grounded theory approach (open, axial, \& selective). Any common themes among the participants were recorded, and only themes that were consistently mentioned were reported in the results.

\section{Rationale for the Method}

Mixed research is very commonly used by educational researchers simply because the two different types of research allow for the different strengths of each method to overlap. This makes it less likely that the researcher will make a mistake (Johnson \& Christensen, 2008). The issue that was chosen to focus on was faculty and staff perceptions of school safety and armed employees. This information was gathered by assessing the results of a mixed questionnaire that participating employees completed. Although not generalizable, the results of this study could serve as a starting point for other schools of similar demographics that may be considering an armed employee policy. 
ARMED EMPLOYEES \& SCHOOL POLICY

\section{Population of the Study}

The population of the study consisted of all classified and certified employees at a rural high school in Southwest Ohio. Since only one high school was used in this study, there is minimal degree of external validity for teachers in other rural high schools. However, the results of the study would be most applicable to classified and certified staff members in mid-sized (350-650 students), rural high schools in the Midwest and of upper-middle socio economic status.

\section{Sample}

Sample criteria. The participants of this study were classified and certified staff members who gave their consent to participate in the study by turning in the anonymous questionnaire. Responses were received from 36 of 49 staff members.

Rationale for sample. Since the topic of school safety has become such a politicized issue, it was important to make sure participants felt as non-threatened as possible when completing this questionnaire. Therefore participants were encouraged to turn in their responses anonymously in order to receive as large a sample as possible. By doing this a reasonable sample size $(n=36)$ was achieved. This number of responses allowed for enough data collection for the study's intended purposes.

Methods of sampling. Sampling from the population occurred through each participant's willingness to complete the anonymous questionnaire and turn it in. All members of the population were given the opportunity to complete the questionnaire, however due to the sensitivity of the topic and/or time constraints only 36 out of 49 members of the population submitted their responses. The sample used for this study constitutes a sample (albeit not random) from all faculty and staff in rural, mid-sized, Midwest high schools. 
ARMED EMPLOYEES \& SCHOOL POLICY

\section{Procedure}

Instruments. A questionnaire with 27 items was the instrument used for data collection. The questionnaire consisted of 18 closed-ended questions and 9-open ended questions. (See Appendix A)

\section{Major constructs.}

1. How do classified and certified employees perceive safety at their school?

2. How do classified and certified employees perceive the suggestion of armed employees?

3. What procedures and/or limitations need to be in place for their school to have an armed employee policy?

Questionnaire items were prepared around these three major constructs (See Appendix A).

Pilot study. A pilot study was conducted via email with eight teachers from different schools around Southwestern Ohio. Participants in the pilot study represented a wide variety of political views, experience levels, type of school districts (rural, suburban, urban), and of the eight participants four were male and four were female. The pilot study was sent to these eight teachers asking for feedback on any questions that may appear confusing, biased, or leading. Their responses led to the evaluation and revision of not only the questions themselves but also the number and types of questions used in the questionnaire.

Data collection method. Only one type of data collection method was used in this study and that was the 27-item questionnaire (Appendix A). The questionnaire did however consist of both closed-ended questions for quantitative purposes and open-ended questions for qualitative purposes. For this project an email explaining the purpose for the research was sent to all employees at the participating high school two days before the questionnaire was distributed. On 
ARMED EMPLOYEES \& SCHOOL POLICY

the day the questionnaire was distributed, a questionnaire was placed inside an envelope with the researcher's name listed as the return address. Participants were then encouraged to return the sealed envelope back to the drop box located in the main office one week after they were distributed.

Relevant ethical considerations. This research posed no harm to the participants involved. However, since the topic had a tendency to be very polarizing participants were instructed to submit their completed questionnaires anonymously in order to encourage participation. Participants were informed that they gave their consent to participate in the study by returning their completed questionnaire to the drop box located in the main office.

Treatment variable. The treatment variable was the school's safety policy. The assessed variables were the faculty and staffs' perceived benefits and limitations of having armed employees. Alternative solutions of reacting to an active shooter were also noted.

Methods of data analysis. All of the questionnaires given to the school staff were first assigned a number and then the responses were manually entered into Microsoft Excel. A master file was used for the initial data entry, and then later the responses were separated into different demographical categories in order to compare and contrast the responses among classified verses certified staff, and male teachers verses female teachers. In order to analyze the quantitative data, a randomization test for a difference in means was constructed for each category in order to test for any statistical significance between two groups. These randomization tests were performed using the web based statistical program at lock5stat.com-StatKey. Results were then reported.

In order to analyze the qualitative data, a three-tiered coding system was used. First, "open coding" was performed by giving labels to describe the responses given by the 
ARMED EMPLOYEES \& SCHOOL POLICY

questionnaire participants. Next, "axial coding” was performed by looking for similar labels and grouping them into common categories. In this stage codes were removed that did not commonly appear and new categories were added for those labels that appeared often. Lastly, "selective coding" was performed by looking for any general themes that might have appeared from the common categories.

Safeguards to internal and external validity. The questionnaire used in this study was carefully constructed and modified based on the results of the pilot study in order to prevent any bias. All questions were created neutrally in order to elicit the participant's honest response, not try to manipulate or lead them to any desired answer. Participants were instructed to turn in the questionnaire anonymously as a way to encourage their honest responses. Participants gave their consent to this study by simply turning in the questionnaire to the drop box left in the main office. All members of the population had a chance to participate so there was no bias shown in who would be included in the sample. However, one possible threat to internal validity was the offer of a chance to win a $\$ 20$ gift card for participating in this study. Since the questionnaires were completed anonymously participants were instructed to turn their name into a separate drop box if they would like to be entered into the drawing. As a result of this offer, some participants may have rushed through the questionnaire or answered some of the questions insincerely.

While the results of this study could be generalized to the entire population of the participating high school, it would not be appropriate to say that the results can be universal for similar high schools. The sample of this study was only taken from one high school so the appropriate population for this study would be that same school. However, for rural schools of similar size and teacher/student demographics, the results of this study might be a good starting point for any school interested in developing an armed employee policy. 


\section{Chapter IV: Quantitative \& Qualitative findings}

\section{Overview}

This study sought to accomplish three tasks: (1) discover the perceptions of safety that classified and certified employees have at their school, (2) discover the perceptions of armed employees that classified and certified staff have, and (3) discover what procedures and limitations should be in place if a school were to adopt an armed employee policy.

Quantitatively, the results show little to no significant difference for any of the above three constructs when comparing male verses female employees. However, there was a statistically significant difference for many of the questions when comparing the responses from classified staff verses certified staff. While almost all staff stated that they thought their school was a safe place to work, some of the common concerns that came up regarding school safety at the participating high school were the lack of solid doors and locks to keep an unauthorized gunman from entering the building, along with a general lack of discussion and drill practice among the staff for reacting to an active shooter. The majority of employees agreed that arming multiple teachers would present the biggest risk of any of the proposed options in the survey due to a lack of experience and training, coupled with issues of maintaining weapon security. Hiring an armed security officer was one of the more favored responses, however a common theme that arose from nearly all participants in the survey was a need to practice and discuss these situations so that everyone would be on the same page should an active shooting ever occur. Lastly, the two general themes that arose when participants were asked how their school should respond to an active shooter were either 1) fight back in some form or another or 2) keep the current procedures in place while practicing and discussing them more.

The closed-ended and open-ended analyzed responses from the participants were 
ARMED EMPLOYEES \& SCHOOL POLICY

separated into three groups regarding the three constructs of this paper. The results are given in the following sections of this chapter.

\section{Perceptions of Safety: Data, Analysis, and Conclusions}

Even though $94.4 \%$ of participants in this study agreed or strongly agreed that their school was a safe place to work, only $66.7 \%$ of the participants thought that there were sufficient procedures in place to protect students and staff in the event of an active shooter. Furthermore, after analyzing the written responses regarding concerns/suggestions that staff members have toward responding to an active shooter, two key themes that emerged after the responses were coded and recoded: (1) the importance of having secure doors to the building and individual classrooms, and (2) the importance of discussing, practicing, and taking drills seriously. One response that came from a certified male instructor stated:

We need a better answer to a back access door that students and staff need to enter and exit several times a day. It is often left open out of convenience. We also have glass windows and doors in the front of the building. One shot could easily break the glass of a door and allow a shooter in.

The importance of having secure doors in this school can also be reflected in the quantitative responses that were received. Of those participating, $94.4 \%$ stated they thought their school was a safe place to work, $86.1 \%$ felt protected from any student physically attacking them, $75 \%$ felt protected from any outsider physically attacking them, and $66.7 \%$ felt like their school had sufficient procedures in place to protect staff and students in the event of an active shooter. The decrease in percentages as you move from internal to external threats indicates that the ability to keep unwanted people from entering the building is a real concern for the staff members of this school. 
Secondly the lack of drill, practice, and discussion regarding the topic of what to do if an active shooter were on school grounds was a common concern among staff members in this section. Several responses indicated that although they believed the school had sufficient procedures in place, there still was a lack of practice and discussion on what to do in certain situations. One such response came from a female certified instructor: "There is a crisis procedure, however it is never discussed, practiced, or key people identified who are to run it." A classified female employee also responded: "We run drills—-but never discuss different situations."

The comparison of classified v. certified responses also showed a statistically significant difference in the responses between the two groups. See Figure 1.
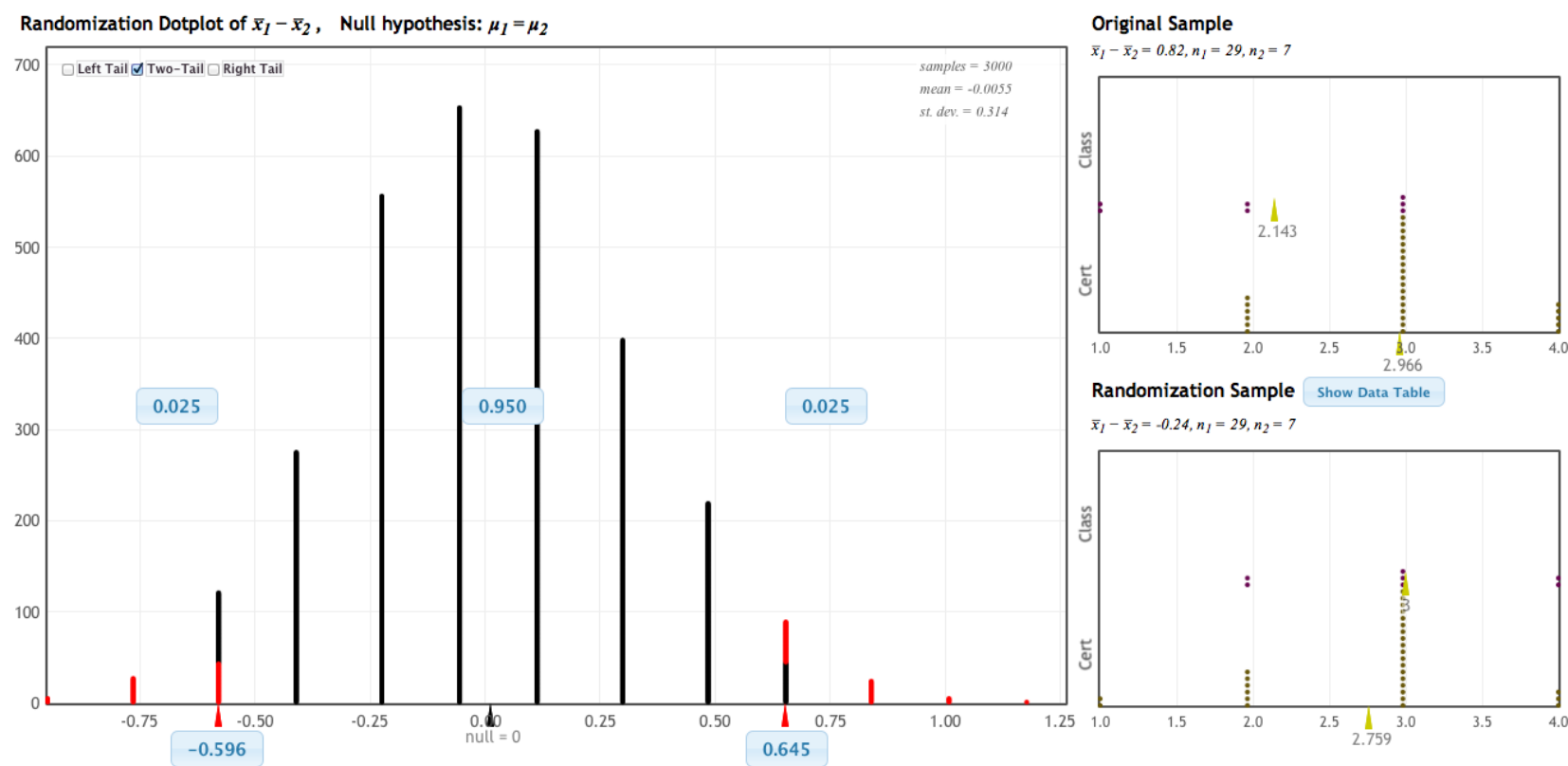

$\bar{x}_{1}-\bar{x}_{2}=-0.24, n_{1}=29, n_{2}=7$

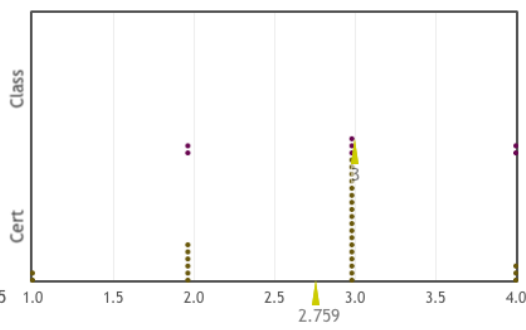

Figure 1. Classified v. Certified perceptions of current procedures to stop an active shooter.

Certified staff were much more likely to feel as if the school had sufficient procedures in place to protect oneself and others against an active shooter when compared to the responses from 
ARMED EMPLOYEES \& SCHOOL POLICY

classified staff. One possible explanation for this would be that classified staff members are often excluded from faculty meetings where this information may be discussed. When asked the questions on whether or not one feels like their school is a safe place to work, one feels protected from a student physically harming them, or one feels protected from an outsider physically harming them, there was no significant difference between either classified and certified employees, or male and female employees (See Appendix B).

\section{Perceptions of Armed Employees: Data, Analysis, and Conclusions}

Participants in the questionnaire were asked to give an approval rating $(1=$ strongly disapprove, 2 = disapprove, $3=$ approve, $4=$ strongly approve) in regards to each of the following scenarios regarding armed employees: 1) allowing multiple teachers to carry a concealed weapon, 2) allowing a single teacher to carry a concealed weapon, 3) allowing multiple administrators to carry a concealed weapon, 4) allowing a single administrator to carry a concealed weapon, 5) allowing retired police officers to serve as substitutes and carry concealed weapons, and 6) allowing security officers to carry concealed weapons. Overall, the idea of hiring armed security officers (3.21 average) was the most favorable followed by allowing retired police officers (3.03) to serve as substitutes and carry concealed weapons. Next, allowing multiple administrators (2.82), multiple teachers (2.71) fell in the middle as far as approval rating are concerned. Lastly, the least favorable suggestions were allowing a single administrator (2.65) to carry a concealed weapon followed by allowing a single teacher (2.52).

When testing for statistical significance between classified and certified staff there was two instances where the difference in means fell outside of the $95 \%$ confidence interval. 
First, classified staff are more likely to approve of allowing multiple teachers to carry concealed weapons on campus. See Figure 2.
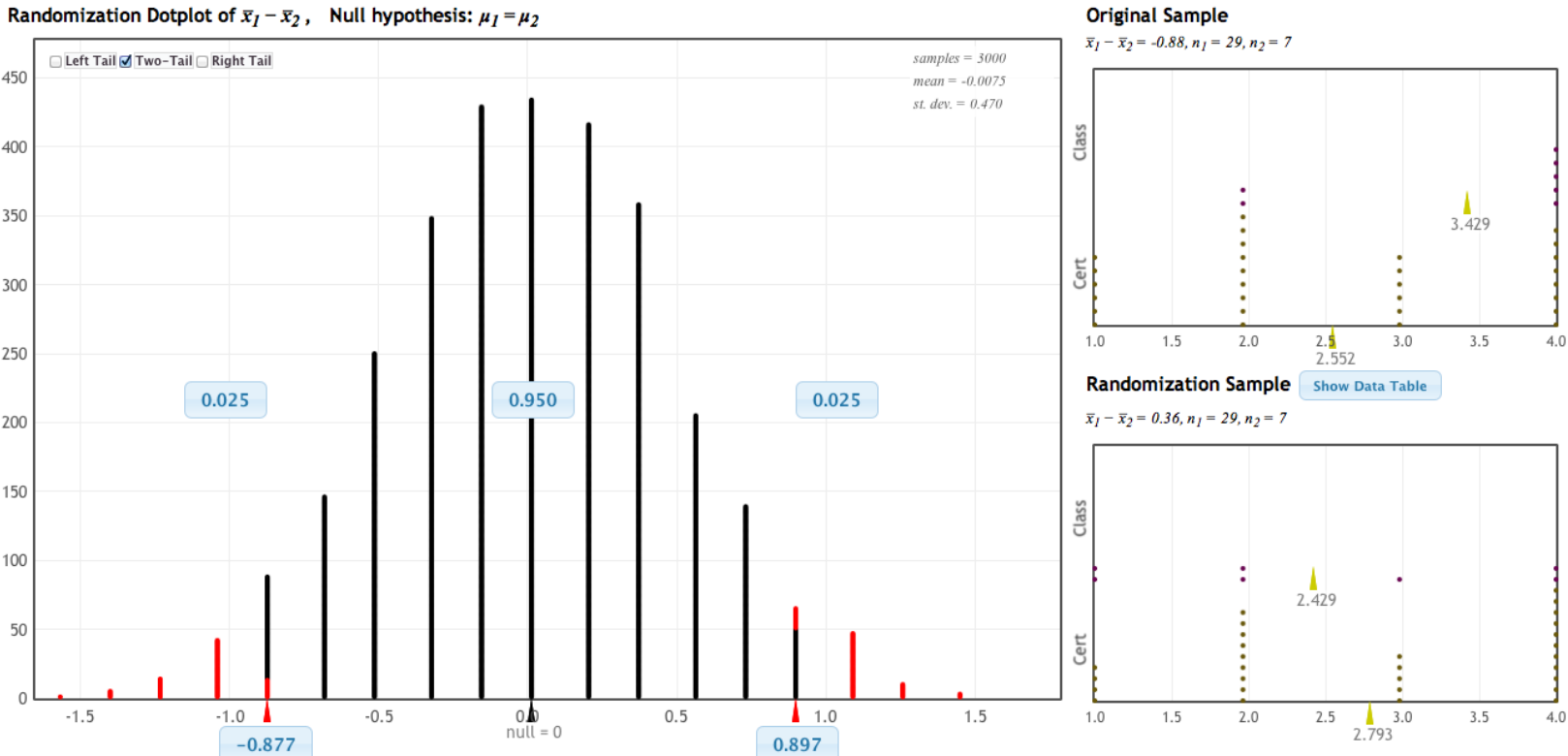

Figure 2. Classified v. Certified perceptions of having multiple, armed teachers.

The average response for certified employees was 2.55 compared to the average of 3.43 for classified employees. The difference between the means (-.88) was outside of the $95 \%$ confidence interval of what you would expect to happen by chance, thus indicating a significant difference between the two groups. 
Secondly, classified staff are also more likely to approve of allowing multiple administrators to carry concealed weapons on campus. See Figure 3.
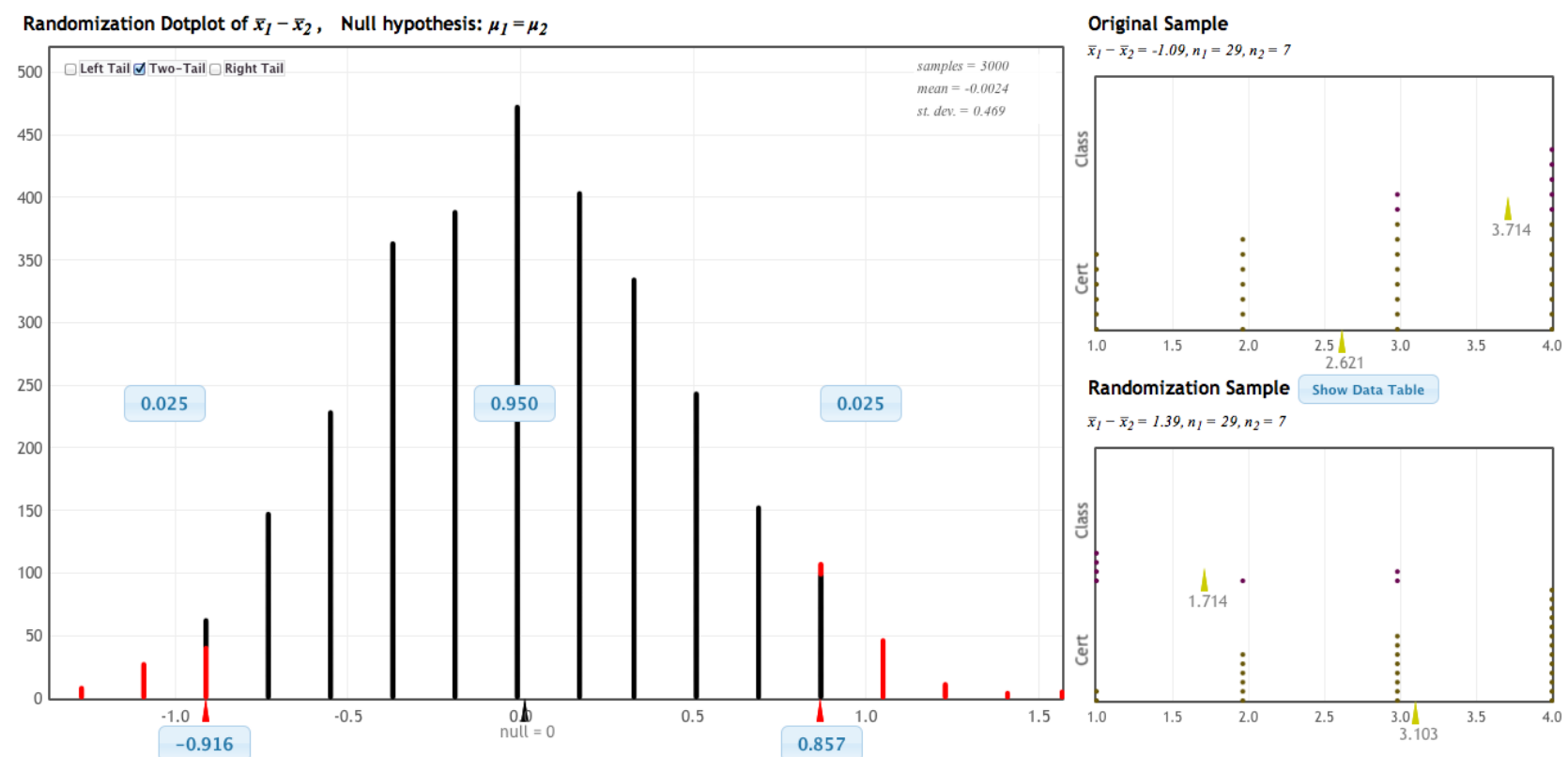

Figure 3. Classified v. Certified perceptions of having multiple, armed administrators.

Classified staff had an average approval rating of 3.71 compared to that of 2.62 for certified staff. There was not a statistically significant difference in the responses between certified and classified staff regarding a single teacher, single administrator, retired police officer, or security guard carrying a concealed weapon on campus. Also, there was not a statistically significant difference in means for any of the six possible scenarios when comparing male and female employee responses. (See Appendix B).

When participants were asked what they felt presented the biggest amount of risk, $91.7 \%$ agreed that either arming a single teacher or multiple teachers would present the most risk. One such response came from a certified male instructor: "While I think this is a good option, I feel you may have a teacher snap on their students and if they have a gun it could get dangerous." 
ARMED EMPLOYEES \& SCHOOL POLICY

A common theme that appeared was that by allowing more teachers to carry there is a significant increase in the possibility for accidents to occur. For those who selected arming a single teacher as presenting the biggest risk, the common theme that arose from the comments was that if that teacher were known, they could become the first target. Also, many who chose single teachers in this category noted it is much more difficult for a single teacher to cover the entire school when compared to multiple teachers.

When asked what scenario presented the least amount of risk, $61.1 \%$ thought that hiring retired police officers would be the best option, followed by $22.2 \%$ suggesting arming multiple teachers. It should be noted that of the $22.2 \%$ who thought arming multiple teachers would present the least amount of risk, all of them selected either a single teacher or single administrator as the option that presented the most amount of risk. Comments by these participants suggest that their idea of risk was not having enough coverage and/or armed employees present to disarm an active shooter, while those who selected multiple teachers as having the most amount of risk indicated that the possibility of accidents, students obtaining these weapons, or teachers "snapping" were there biggest concerns. Also, it should be noted that option 6 (allowing security officers to carry concealed weapons) was omitted from this question. Previous data suggests that most teachers would agree having an armed security officer would present the least amount of risk, however many districts just do not have the money to hire these active officers (Shah, 2013d).

The last question in this section was "which of the proposals mentioned above would they most likely support as a means to stop an active shooter" (sans armed security officers)? Of the responses, $36.1 \%$ thought that allowing armed, retired officers to serve as substitutes would be the best option, $30.6 \%$ would most support having multiple teachers carry concealed weapons, 
ARMED EMPLOYEES \& SCHOOL POLICY

19.4\% would prefer having multiple or a single administrator carry concealed weapons, and $13.9 \%$ would not support having any armed employees on campus. It should be noted that there was not a single participant who selected allowing a single CCW licensed teacher as the option they would most support.

A certified male instructor who selected hiring retired police officers to serve as armed substitutes stated the following as his reasoning: "If retired officers are on site all the time there is a chance to stop a single shooter. They can protect on a minimal basis until more police arrive on scene”. A classified female staff member who selected having multiple teachers carry concealed weapons also gave this reason for her selection: "By having multiple carriers, there would always be someone there to protect. As the NRA stated, the only way to stop a bad guy with a gun is a good guy with a gun".

Overall, after analyzing the responses on all questions in the section, the questionnaire results indicated that the certified staff at the participating school were more inclined to be concerned with the possibility of accidents occurring while the classified staff appear to be more worried about having enough armed employees to stop or isolate an active shooter, should an active shooting ever occur on campus. Of the classified staff, $57 \%$ selected having multiple, armed teachers as the method they would most likely support, compared to only $24 \%$ of certified staff selecting the same response.

\section{Policy Considerations for Armed Employees}

As with any policy a district considers implementing (let alone one that involves placing armed employees in close proximity to children), a district must carefully weigh the advantages and disadvantages. Participants in the study were asked to give their input regarding concerns, safeguards, and any other considerations that they might raise if they were to hypothetically 
ARMED EMPLOYEES \& SCHOOL POLICY

serve on a committee overseeing the development of an armed employee policy for their district. The questionnaire results revealed that the staff overwhelmingly raised three main concerns: 1 ) lack of training, 2) lack of weapon security, 3) lack of teacher mental health screenings. Nearly $47 \%$ of the responses mentioned lack of training as key concern. One such response came in the form of a list from a certified female instructor:

- $\quad$ Lack of continuous training

- $\quad$ Lack of training with students- large groups - classes, halls, etc.

- $\quad$ Lack of training if panic in groups occurs.

- Who stays in the classroom with students if teacher leaves to pursue shooter? A variety of situations and questions would have to be addressed before a school could allow teachers to carry concealed weapons.

The second main concern (indicated by $36 \%$ of participants) was the lack of maintaining weapon security. Thirdly, it was clear from the responses that giving psychological evaluations to those who carry concealed weapons on campus was another main concern. One response from a certified instructor describes their concerns on both weapon security and psychological issues:

You don't know a teacher, staff, or administrators mental status. What if a staff member you are unaware of received their $\mathrm{CCW}$ certification, obtained a gun, was okayed to carry at school, then began having personal issues, started taking antidepressants, then quit, then began having delusional thinking, and then became postal on everyone at school? In light of these concerns, there are several safeguards that should be in place before a school should allow an armed employee on campus. The staff overwhelming mentioned the importance of extensive training and background checks before a staff member should be 
ARMED EMPLOYEES \& SCHOOL POLICY

approved to carry a concealed weapon. Not only did the participants mention extensive training as a necessity, but they also would request that this training be continuous and involve simulations reflecting the high stress situations that an active shooter would present. A male certified instructor responded as follows: "The teacher must be properly trained and the weapon must be secured in a way that it is very difficult for some one other than the teacher to get it". Another certified male listed the following safeguards that must be in place:

- The weapon must be secured in a safe

- The staff who carry should remain anonymous

- The location of the safe in each room should remain a secret

- Training on a regular basis would be needed for those CCW

- A partnership with the local police department would be helpful.

A classified female gave the following response regarding the same issue:

I think school safety training classes need to be given, not just a class "talking" about safety (lock your doors, turn out lights, hide out of view of the shooter) but a class simulating a real shooting situation. I would feel more comfortable with these guidelines. As a final question, participants were asked to describe what they thought would be the best way for a school to respond to an active shooter. Approximately $33.3 \%$ thought that the current procedures should say in place, however most from this group thought that those procedures should be practiced more and in conjunction with the local police department. Next, $36.1 \%$ thought that the school should fight back via armed employees. The responses in this category included arming teachers, administrators, security guards, and retired police officers serving as substitute teachers. Another $13.9 \%$ thought that the school should fight back/ isolate the shooter using whatever means necessary without specifically mentioning guns, and finally 
ARMED EMPLOYEES \& SCHOOL POLICY

the remaining $16.7 \%$ issued no response. It should be noted that $53 \%$ of males and only $23.8 \%$

of female participants viewed fighting back via armed employees as the best way for their school to respond to an active shooter. There was no significant difference in the viewpoints of certified verses classified staff regarding the best way for their school to fight back.

\section{Summary}

In summary, this study exposed the importance of having extensive training, background checks, and safeguards in place before a school plans on allowing armed employees on campus and adopting an armed employee policy. There is no consensus in place and the results from this study show that we are far from an agreement on whether or not schools should allow armed employees on campus. When asked the question, "Would you be willing to carry a concealed weapon on campus as a means to stop an active shooter", the results were far from one-sided: $38.8 \%$ of employees said that they would be willing to carry a concealed weapon, $30.6 \%$ said they would not be willing to carry, and another $30.6 \%$ said that they were unsure. As one participant stated: "Twenty years ago, who would have even thought that we would have to worry about student gunmen?" 


\section{Chapter V: Discussion and Implications}

After analyzing the results of this mixed-methods study, it has become clear that the issue of how to stop an armed gunman in our schools is extremely complicated. Opinions differ greatly and unfortunately since the topics of gun control and armed employees are highly politicized, responses and suggestions to the problem are often automatically polarized to one side of the spectrum or the other.

While there has been much discussion and debate about the topic of school shootings, little research exists regarding how teachers and other staff members feel towards current procedures and other possible solutions. The intent of this study is to provide some qualitative and quantitative data towards how classified and certified staff members perceive the proposed solution of arming teachers, along with other safety and policy concerns. Also, whatever course of action a school decides to take in regards to reacting to an active shooter, the plan should be widely discussed, practiced, and reviewed regularly.

\section{Interpretation of the Results}

The need for solid physical barriers. While $94.4 \%$ of participants in this study thought that their school was a safe place to work, only $66.7 \%$ believed that there were sufficient procedures in place to protect staff and students in the event of an active shooter. Also, many participants stated their concerns over both the internal classroom doors and the external doors that could allow an outsider into the school. As evidenced in the December 2012 shooting at Sandy Hook, current procedures such as controlled access do very little to protect against an active shooter if there are glass doors or windows ("After Newtown", 2013). Protecting students from possible armed gunmen entering the school along with protecting students from armed gunmen entering individual classrooms was a major concern for the participants in the study. 
ARMED EMPLOYEES \& SCHOOL POLICY

The need for discussion and drill. As mentioned above, only $66.7 \%$ of participants in this study believed that there were sufficient procedures in place to protect their school from an active shooter. Of this group, numerous participants said that these procedures were not practiced or discussed. In order to ease staff concerns and also to get everyone on the same page a crisis plan needs to be developed and distributed among staff. Individual situations also need to be discussed and practiced. In order to create a safe environment for students it starts by providing the staff with the necessary training and instruction in order for everyone to feel confident in their ability to keep each other safe. Also many staff members stressed the need for these crisis plans to be developed and practiced in conjunction with local police, fire, and rescue departments.

The need for a way to fight back. Of the participants in this study $33.3 \%$ thought that the best way for a school to respond to an active shooter would be to continue to use the current procedures - with increased drill and discussion, 50\% thought that the school should fight back in some form or another, and the other $16.7 \%$ left no response. Fighting back can take many forms, some including armed employees and some not. Some examples of non-lethal interventions include the use of hiding in blind spots and then jumping the attacker when he passes (JeeHae, 2013), along with the use of stun guns or rubber bullets. The most preferred method of fighting back via armed employees would be to hire an armed security guard, then a retired police officer to serve as a substitute, and lastly multiple armed teachers and/or administrators. The main concerns that participants in this study had were the security of the weapon, mental health of the gun handler, and the necessity of intense, continuous training for any employee before carrying a weapon on campus. The goal should be to provide a quick reaction with as minimal risk as possible. 


\section{Potential Applications of the Findings}

Invest in sturdier physical barriers. When certified and classified staff members were asked about the safety concerns they had at their school, numerous participants mentioned the lack of secure internal and external doors. There are many ways to improve the physical barriers that could separate students and staff from an active shooter in the event of an emergency. First of all controlled access into the building is a must, however the controlled access point must have enough protection that a potential shooter couldn't simply shoot through the side windows or door windows and gain access that way. Some potential options include replacing glass doors or possibly using a bulletproof spray or film to cover these glass doors or windows (Molnar, 2013). Of course if the shooter is already inside the building there are a number of other protective measures schools can take as well. For one, replacing old classroom doors with sturdier versions should be considered, along with the use of "prop and lock" doors that could be activated to isolate an active shooter from other parts of the school. Another step that schools could take is through the investment of bullet-proof $18 \times 20$ inch whiteboards that are now available (Molnar, 2013), however the previous possibilities mentioned should take priority over this option.

Invest in training. Responses by the participants of the study suggest that it would be extremely beneficial for a school district to invest in some form of training for dealing with an active shooter. Many participants in the study noted the lack of discussion and drill regarding what they would do if a shooting actually occurred, so the need to educate faculty and staff about the procedures could literally be the difference between life and death. There are many programs available free of charge such as the 3-4 hour program offered by the Ohio Attorney General's office. This would require a decent investment of time, however the half-day that this training 
ARMED EMPLOYEES \& SCHOOL POLICY

would take up could go far in creating a sense of safety among staff. Schools should also discuss and practice their plans with staff and students regularly in concordance with the local police department. Also, mentioned in the next section is the availability of self-defense disarming training for teachers should the need to fight back ever occur in order to save the lives of their students.

Invest in "shooter disabling" security. In the results from the questionnaire, many classified and certified staff indicated that they believed the best way for their school to react to an active shooter would be to fight back in some form or another. While all indicated their concerns over allowing teachers to carry concealed weapons, the suggestion of hiring a security guard or even allowing retired police officers to serve as substitutes proved to be some of the more favorable options with the least amount of risk involved. However for schools who can not afford security officers and are considering allowing staff to carry concealed weapons, they should take note of the need for continuous, intensive training and mental health screenings that should be required for all potential armed employees. If schools are considering having any armed personnel in the building, they should also choose the option that would present the best case for maintaining weapon security coupled with the option that requires the greatest amount of realistic and continuous training. If schools are not considering having any armed personnel in their buildings, there are other options available that can disable an active shooter such as the use of stun guns and rubber bullets (JeeHae, 2013). JeeHae (2013) also noted that there are also available training sessions available that instruct teachers on how to disable a gunman through hiding in blind spots before attacking along with the use of their hands, feet, knees and elbows to remove the gun from the shooter. 
ARMED EMPLOYEES \& SCHOOL POLICY

\section{Relation of the Results to Literature}

While there has been minimal research completed regarding the perceptions school staff members have toward arming employees, the researcher was able to find some nationwide survey results that further validated the findings of this study. First, a survey completed by teachers during 2013 found that $92 \%$ of those polled stated that they felt safe in school, while only $69 \%$ believed that their school was safe from gun violence ("Survey," 2013). This compared favorably to the results of this study in which $94.4 \%$ of participants stated they thought that their school was a safe place to work and only $66.7 \%$ thought that there were sufficient procedures in place in order to protect staff and students from an active shooter.

Another survey that compared favorable to the results of this study was also completed in 2013 and stated that only $20 \%$ of participating teachers said that their school drills regularly on how to deal with an armed intruder (Shah, 2013d). Numerous participants in this study stated that the participating school had a plan in place, however it was not discussed or practiced enough. Although schools have numerous other initiatives and mandates on their plate, the need to be ready for an emergency, in particular an active shooter, is not something that should be overlooked.

Next, the percentage of teachers who would be likely to carry a weapon to school if permitted also compared favorably to the results gathered from this study. When asked the question, "Would you be willing to carry a concealed weapon on campus as a means to stop an active shooter", $38.8 \%$ of employees said that they would be willing to carry a concealed weapon. In the 2013 nationwide survey mentioned in the paragraph above, $72 \%$ of teachers stated that they would be unlikely to carry a weapon even if they were allowed (Shah, 2013d). 
Both the national survey and the researcher's results show that roughly one-third of teachers would be willing to carry a concealed weapon if given the opportunity.

One other similarity that was observed connecting the results of this study to the literature involved a common reason why rural schools might want to consider adopting an armed employee policy - the increased response time for local authorities. The response time for the participating high school would take a minimum of five minutes before first responders would arrive on the scene. Since $27 \%$ of school shootings are over within the first five minutes and nearly half of all school shootings are over within fifteen minutes (JeeHae, 2013), the ability to respond and react quickly was one safety concern raised by some participants in the study.

\section{Biblical Integration}

When people refer to the issues of gun control and religion, a negative connotation of "those who cling to their guns and religion" is commonly brought up as a stereotype for conservative Christians. However even within the church, the topic of guns and gun control is a hotly debated issue. While the Bible does not specifically mention the use of guns, there are many passages involving weapons and self-defense that are considered applicable. Typically believers fall into one of two groups when it comes to this issue of guns: the "pacifism" group or the "protector" group.

Members of the "pacifism" group commonly cite the following three main passages in

\section{Scripture:}

Exodus 20:13 - You shall not murder.

Matthew 5:38 \& 39 - "You have heard that it was said, 'Eye for eye, and tooth for tooth.' But I tell you, do not resist an evil person. If someone strikes you on the right cheek, turn to him the other also." 
ARMED EMPLOYEES \& SCHOOL POLICY

Matthew 26:52 - "Put your sword back in its place," Jesus said to him, "for all who draw the sword will die by the sword."

Members of the "pacifism" group are against any sort or violent response to someone else physically attacking another.

Members of the "protector" group take a different approach. Some of the more common passages in scripture that are used to justify using force to protect oneself and family include:

1 Samuel 25:13 - David said to his men "Put on your swords!" So they put on their swords and David put on his ..."

Exodus 22:2-3 - "If a thief is caught breaking in and is struck so that he dies, the defender is not guilty of bloodshed; but if it happens after sunrise, he is guilty of bloodshed."

Luke 22:35-36 - Then Jesus asked them, "When I sent you without purse, bag or sandals, did you lack anything?" "Nothing," they answered. He said to them, "But now if you have a purse, take it, and also a bag; and if you don't have a sword, sell your cloak and buy one."

Members of the "protector group" would argue that when pacifists use Matthew 26:52 as a call for non-violence against attackers, Jesus is simply telling Peter to "put his weapon back in its place" or in other words "now is not the time." Jesus is not saying that Peter shouldn't carry a weapon because in Luke 22:35-36 Jesus actually instructed his disciples to buy a sword. Also, many members of the "protector group" believe that in Exodus 22:2-3 the distinction made between justifying a self-defense murder and protecting one's self and family during a break-in has little to do with whether it is at night or during the day, but rather knowing if the intent of a 
criminal is to cause physical harm or simply to steal property. Regardless, Scripture does make it clear that Christians should not partake in offensive violence.

So how does all of this apply to including or not including armed employees in schools? The courts have previously made it clear that schools are to operate "in loco parentis" or in place of the parents while students our in their care (Rumel, 2013). Rumel (2013) also points out that in light of the Castaldo v. Stone (2001) ruling following the 1999 shootings at Columbine "the courts have recognized that schools, administrators, and teachers, based on their in loco parentis status, must supervise and/or protect students from foreseeable harm to both their physical and emotional well-being". Also as Christians we are called to defend the defenseless and to stand up for those who can't stand up for themselves. Schools should use whatever means necessary in order to protect their students from acts of violence. Whether this means using lethal or nonlethal force is a decision that school districts must carefully weigh based on their own individual needs and situations.

\section{Strengths of the Study}

This project involved using a mixed method approach to analyze the results in order derive any common themes regarding the perceptions school employees have toward school safety and armed employees. Through the collection of both quantitative and qualitative data, the researcher was able to quickly gather numerical data in order to calculate percentages and test for any statistical difference between groups (classified verses certified, male verses female), while also leaving room for the participants to express their thoughts and opinions via openended responses. All classified workers and certified employees at the participating school were invited to take part in the questionnaire, and approximately $73.5 \%$ did respond. Also, while other studies have examined possible causes and preventative efforts in regards to school 
ARMED EMPLOYEES \& SCHOOL POLICY

shootings, this study was the first of kind examining the perceptions classified and certified staff members of a rural school district have toward school safety and the proposed solution of arming employees.

\section{Limitations of the Study}

One major limitation of this study was the small numbered of responses from classified employees that were received (7). The researcher did receive a significant number of responses from certified employees (29), however since the survey was given during the last two weeks of the school year time constraints prevented the researcher from being able to analyze any of the data and count number of responses before the school year had already ended. Since the survey was completed anonymously and was completed on a paper copy, it would have been near impossible to track down those who had not yet completed the survey. Also, it was a sensitive issue and the researcher didn't want to push it further than he already had through emails along with the emails from the building principal.

Although there was a lot of very detailed feedback received from many of the participants, a good portion of those that completed the survey left some questions blank or left simple one-two word responses that made the open-ended questions difficult to analyze.

Finally, another limitation of this study is the lack of external validity since only one rural school in southwestern Ohio was used for this study. While the participants in this study are a great representation of the entire population of the participating high school, in order to generalize this study across the entire state or country one would need to incorporate multiple schools with similar demographics from a variety of different locations. However for mid-sized rural schools considering adopting an armed employee policy, the data from this study would serve as a good starting point. 
ARMED EMPLOYEES \& SCHOOL POLICY

\section{Suggestions for Future Research}

If this study were to be repeated, it would be suggested to use a web-based program to complete the survey. It is more convenient for those filling it out and it allows for collecting and analyzing data to be more time efficient. Also, it allows the participant to complete the survey anywhere where there is a computer, rather than having to carry around the paper copy and worry about losing it.

Regarding this study, another suggestion for future research would be to incorporate multiple schools with similar demographics in order to increase the sample size as well the external validity of the study. Some other topics of interest that could serve as follow-ups to this study are: staff perspectives of armed employees at suburban or urban schools; comparing staff perspectives of armed employees at rural, suburban, and urban schools; and student perspectives of armed employees. However with the latter option it might be very difficult to gain administrative approval in order to conduct the research on school grounds. Comparing faculty and staff perspectives on armed employees by locale (within a single state or multiple states) would be another interesting item to investigate.

Some other topics that could serve as derivatives to this research would include investigating if liability insurance premiums would increase for schools if they were to allow armed employees on campus. If so, how would those increased premiums compare to the cost of simply hiring single or multiple armed guards? Also, before a school would implement an armed employee policy it would be interesting to discover how parents in the district feel about allowing armed employees on campus. Results could then be analyzed and compared with the political views of those participating parents. Lastly, it would be beneficial to conduct research 
ARMED EMPLOYEES \& SCHOOL POLICY

comparing which options for improving security would be the most cost effective — hiring armed guards or increasing physical barriers? 


\section{References}

After Newtown: A look at school safety. (2013). Curriculum Review, 52(6), 3-3.

Beaty, L. A., \& Alexeyev, E. B. (2008). The problem of school bullies: What the research tells us. Adolescence, 43(169), 1-11.

Bliss, M., Emshoff, J., Buck, C., \& Cook, S. (2006). Parents' perceptions of causes of and solutions for school violence: Implications for policy. Journal of Primary Prevention, $27(3), 265-281$.

Brown, B. (2005). Controlling crime and delinquency in the schools: An exploratory study of student perceptions of school security measures. Journal of School Violence, 4(4), 105125. doi:10.1300/J202v04n04_07

Buck, S., Yurvati, E., \& Drake, D. (2013). Teachers with Guns: Firearms discharges by school teachers, 1980-2012. Center for Homicide Research. Retrieved from http://homicidecenter.org/wp-content/uploads/2013/08/Teachers-with-GunsRESEARCH- REPORT-FINAL1.pdf

Cowan, K. C. 1., \& Rossen, E. (2013). Response to the unthinkable: School crisis response and recovery. Phi Delta Kappan, 95(4), 8-12.

Cray, M., \& Weiler, S. C. (2011). Policy to practice: A look at national and state implementation of school resource officer programs. Clearing House, 84(4), 164-170. doi:10.1080/00098655.2011.564987 
Crews, G. A., Crews, A. D., \& Burton, C. E. (2013). The only thing that stops a guy with a bad policy is a guy with a good policy: An examination of the NRA's "National school shield” proposal. American Journal of Criminal Justice, 38(2), 183-199. doi:10.1007/s12103-013-9202-x

Daniels, J. A., Bradley, M. C., Cramer, D. P., Winkler, A. J., Kinebrew, K., \& Crockett, D. (2007). The successful resolution of armed hostage/barricade events in schools: A qualitative analysis. Psychology in the Schools, 44(6), 601-613. doi:10.1002/pits.20250

Daniels, J. A., Volungis, A., Pshenishny, E., Gandhi, P., Winkler, A., Cramer, D. P., \& Bradley, M. C. (2010). A qualitative investigation of averted school shooting rampages. The Counseling Psychologist, 38(1), 69-95. doi:10.1177/0011000009344774

De Apodaca, R., Flores, Brighton, L. M., Perkins, A.M., Jackson, K.M., \& Steege, J.R. (2012). Characteristics of schools in which fatal shootings occur. Psychological Reports, 110(2), 363-377. doi:10.2466/13.16.PR0.110.2.363-377

DeAngelis, K. J., Brent, B. O., \& Ianni, D. (2011). The hidden cost of school security. Journal of Education Finance, 36(3), 312-337.

Department of Justice, Washington, DC National Inst. of Justice. (2002). Preventing school shootings: A summary of a U.S. secret service safe school initiative report.

Dewine, M. (2013). Ohio’s Concealed Carry Laws. Retrieved April 8, 2013, from http://www.ohioattorneygeneral.gov

Ericksen, G., (2013). Safer reactions. American School \& University, 86(1), 22-26. 
ARMED EMPLOYEES \& SCHOOL POLICY

Estep, S. (. (2013). Crisis planning: Building enduring school-community relationships. Delta Kappa Gamma Bulletin, 79(3), 13-20.

Fein, A. H., Carlisle, C. S., \& Isaacson, N. S. (2008). School shootings and counselor leadership: Four lessons from the field. Professional School Counseling, 11(4), 246-252. doi:10.5330/PSC.n.2010-11.246

Ferguson, C. J., Coulson, M., \& Barnett, J. (2011). Psychological profiles of school shooters: Positive directions and one big wrong turn. Journal of Police Crisis Negotiations, 11(2), 141-158. doi:10.1080/15332586.2011.581523

Frederick, J. (1999). Do as I say, not as I do: Why teachers should not be allowed to carry guns on school property. Journal of Law \& Education, 28(1), 139-143.

Fritz, G. K., \& Radka, D. (2010). Weapons in schools. Brown University Child \& Adolescent Behavior Letter, 26(2), 8-8.

Garza, K. (2002). School security moves into the digital age. T.H.E. Journal, 30(5), 44-45.

Gastic, B. (2010). Students and school adults: Partners in keeping schools safe. Journal of School Health, 80(6), 269-270.

Hankin, A., Hertz, M., \& Simon, T. (2011). Impacts of metal detector use in schools: Insights from 15 years of research. Journal of School Health, 81(2), 100-106.

Harrold Independent School District. (2013). Concealed handgun policy. Retrieved March 2, 2013, from http://harroldisd.net/vnews/display.v/ART/4c080dfbee1f9 
Haselswerdt, M. V., \& Lenhardt, A. M. C. (2003). Reframing school violence: Listening to voices of students. Educational Forum, 67(4), 326-336.

doi: $10.1080 / 00131720308984581$

Hirsh, L. (2013). Brothers in arms control: Introducing Australian-style gun control in the United States. Macquarie Law Journal, 12, 81-108.

Hong, J., \& Eamon, M. (2012). Students' perceptions of unsafe schools: An ecological systems analysis. Journal of Child \& Family Studies, 21(3), 428-438. doi:10.1007/s10826-0119494-8

Howard, P. K. (2005). Parents' beliefs about children and gun safety. Pediatric Nursing, 31(5), 374-379.

JeeHae, H. L. (2013). School shootings in the U.S. public schools: Analysis through the eyes of an educator. Review of Higher Education \& Self-Learning, 6(22), 88-119.

Johnson, B., \& Christensen, L. (2008). Educational research: Quantitative, qualitative, and mixed approaches. (3rd ed.). Thousand Oaks, CA: Sage Publications, Inc.

Johnson, S. L., Burke, J. G., \& Gielen, A. C. (2011). Prioritizing the school environment in school violence prevention efforts. Journal of School Health, 81(6), 331-340.

Kanan, L. M. (2010). When students make threats. Tech Directions, 70(5), 31-35.

Kennedy, M. (2007). Preparing the plan. American School \& University, 79(12), supplement. 
ARMED EMPLOYEES \& SCHOOL POLICY

Kleck, G. (2009). Mass shootings in schools: The worst possible case for gun control. American Behavioral Scientist, 52(10), 1447-1464. doi:10.1177/0002764209332557

Koper, C. S., \& Roth, J. A. (2002). The impact of the 1994 federal assault weapons ban on gun markets: An assessment of short-term primary and secondary market effects. Journal of Quantitative Criminology, 18(3), 239-266.

Langman, P. (2009). Rampage school shooters: A typology. Aggression \& Violent Behavior, 14(1), 79-86. doi:10.1016/j.avb.2008.10.003

Maxwell, L. A. (2007). 'Copycatting' may produce more threats. Education Week, 26(34), 1616.

Molnar, M. (2013). Districts invest in new measures to boost security. Education Week, 33(5), 119.

Mongan, P., \& Walker, R. (2012). "The road to hell is paved with good intentions": A historical, theoretical, and legal analysis of zero-tolerance weapons policies in american schools. Preventing School Failure, 56(4), 232-240. doi:10.1080/1045988X.2011.654366

Nieto, M. (2011). The changing landscape of firearm legislation in the wake of McDonald v. city of Chicago, 130 S. CT. 3020 (2010). Harvard Journal of Law \& Public Policy, 34(3), 1117-1130.

Obeng, C. (2010). Should gun safety be taught in schools? Perspectives of teachers. Journal of School Health, 80(8), 394-398. 
ARMED EMPLOYEES \& SCHOOL POLICY

Ohio Rev. Code. $§ 109.78$ (2000), available at http://codes.ohio.gov/orc/109.78

Paccione-Dyszlewski, M. (2013). Trauma, children, and the media: What is ethical coverage? Brown University Child \& Adolescent Behavior Letter, 29(3), 8-8.

Pack, L. (2013, January 17). Sheriff proposes plan for armed personnel in schools. Middletown Journal, pp. 1.

Patten, R., Thomas, M. O., \& Wada, J. C. (2013). Packing heat: Attitudes regarding concealed weapons on college campuses. American Journal of Criminal Justice, 38(4), 551-569. doi:10.1007/s12103-012-9191-1

Pittman, E. (2010). Police departments connect to school district camera feeds to aid incident response. Education Digest, 76(3), 62-64.

Price, J. H., Murnan, J., \& Thompson, A. J. (2005). Elementary school teachers' involvement in firearm safety education. Journal of School Health, 75(3), 105-111. doi:10.1111/j.17461561.2005.tb06650.x

Razi, A., \& DeChillo, N. (2005). High schools respond to crises: Lessons learned. Journal of School Violence, 4(2), 115-131. doi:10.1300/J202v04n02_07

Ripley, A. (2013). Your brain under fire. (cover story). Time, 181(3), 34-41.

Robers, S., Kemp, J., Truman, J., National Center for E. S., \& US Department of Justice, Bureau of Justice Statistics. (2013). Indicators of school crime and safety: 2012. (NCES 2013036/NCJ 241446). National Center for Education Statistics. 
ARMED EMPLOYEES \& SCHOOL POLICY

Robers, S., Zhang, J., and Truman, J. (2012). Indicators of School Crime and Safety: 2011

(NCES 2012-002/ NCJ 236021). National Center for Education Statistics, U.S.

Rumel, J. E. (2013). Back to the future: The in loco parentis doctrine and its impact on whether K-12 schools and teachers owe a fiduciary duty to students. Indiana Law Review, 46(3), 711-751.

Shah, N. (2013a). Downside seen in rush to hire school-based police. Education Week, 32(24), 115.

Shah, N. (2013b). Safety plan for schools: No guns. Education Week, 32(27), 1-14.

Shah, N. (2013c). Shootings revive debates on security. Education Week, 32(15), 1.

Shah, N. (2013d). Survey: Most teachers not likely to carry guns. Education Week, 32(23), 5-5.

Shah, N. (2013e). Teachers already armed in some districts. Education Week, 32(21), 1.

Survey: Do teachers feel safe in school? (2013). District Administration, 49(4), 20-20.

Swezey, J. A., \& Thorp, K. A. (2010). A school shooting plot foiled. Journal of Research on Christian Education, 19(3), 286-312. doi:10.1080/10656219.2010.526458

Taylor, K. R. (2008). Should teachers carry guns? Principal Leadership: Middle Level Edition, $8(8), 60-62$. 
Thompson, S., \& Kyle, K. (2005). Understanding mass school shootings: Links between personhood and power in the competitive school environment. Journal of Primary Prevention, 26(5), 419-438.

Trotter, A. (2005). Schools wrestle with issue of armed guards. Education Week, 24(30), 1-16.

Ujifusa, A. (2013). Legal, logistical concerns seen in call to arm adults. Education Week, 32(15), 16-17.

Warnick, B. R., Johnson, B. A., \& Rocha, S. (2010). Tragedy and the meaning of school shootings. Educational Theory, 60(3), 371-390.

Weiler, S. C., \& Cray, M. (2011). Police at school: A brief history and current status of school resource officers. Clearing House, 84(4), 160-163. doi:10.1080/00098655.2011.564986

What's working. (2013). Curriculum Review, 52(6), 6-9.

Wigley, S., \& Fontenot, M. (2010). Crisis managers losing control of the message: A pilot study of the virginia tech shooting. Public Relations Review, 36(2), 187-189. doi:10.1016/j.pubrev.2010.01.003

Wilson-Simmons, R., Dash, K., Tehranifar, P., O'Donnell, L., \& Stueve, A. (2006). What can student bystanders do to prevent school violence? perceptions of students and school staff. Journal of School Violence, 5(1), 43-62. doi:10.1300/J202v05n01_04

Zubrzycki, J., \& Shah, N. (2013). Federal advice on school intruders worries experts. Education Week, 32(36), 14-14. 


\section{Appendix A}

\section{School Safety/Armed Employee Questionnaire}

As a full- or part-time school employee you are invited to participate in this study investigating how school employees perceive the different proposals regarding armed employees in schools. While there are no benefits for you as a participant (other than being entered into a drawing for a gift card) there is minimal risk involved as all responses will be collected anonymously and kept confidential - in no way will your answers be connected back to you. Completing and returning this questionnaire constitutes you giving your consent to participate. Your complete and honest answers are appreciated. Thank you and please return your completed questionnaire to the main office on or before May $17^{\text {th }}$.

1. Are you a part-time or full-time school employee?

\section{Yes ---- > Please Go to Question 2 \\ No ---- > Please Do Not Complete This Questionnaire Because It Is Only Focused On The Perceptions Of Full- or Part-time School Employees. Thanks Anyway For Agreeing To Participate.}

The first section will deal with your general perceptions of safety at your school. Please respond with (1) strongly disagree, (2) disagree, (3) agree, or (4) strongly agree. (Circle one response for each item.)

Strongly

Disagree

2. My school is a safe place to work.

3. I feel protected from any student physically harming me while at school.

4. I feel protected from any outsider (nonstudent) physically harming me while at school.

5. I feel that my school has sufficient procedures in place to protect others and myself in the event of an active shooter.

$\begin{array}{llll}1 & 2 & 3 & 4 \\ 1 & 2 & 3 & 4 \\ 1 & 2 & 3 & 4\end{array}$

1

2

4

4

4

4
Strongly Disagree $\quad$ Agree $\quad$ Agree

6. What concerns/suggestions, if any, would you have in order for your school to sufficiently respond to an active shooter? 
The next section will deal with your views on some of the more recent proposals for responding to an active shooter. Please rate each of the given proposals based on whether or not you would approve or disapprove of each proposal as a means for stopping an active shooter. Please respond with (1) strongly disapprove, (2) disapprove, (3) approve, or (4) strongly approve.

\section{(Circle one response for each item.)}

Strongly

Disapprove

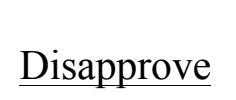

1

Allowing multiple, Board approved, CC
(Carry a Concealed Weapon) licensed teachers to carry concealed weapons on campus.

8. Allowing a single, Board approved, $\mathrm{CCW}$ licensed teacher to carry a concealed weapon on campus.

9. Allowing multiple, Board approved, $\mathrm{CCW}$ licensed administrators to carry concealed weapons on campus.

10. Allowing a single, Board approved, $\mathrm{CCW}$ licensed administrator to carry a concealed weapon on campus.

11. Allowing Board approved, $\mathrm{CCW}$ licensed (retired) police officers to serve as substitute teachers and carry a concealed weapon on campus.

12. Allowing Board approved, $\mathrm{CCW}$ licensed security officers to carry concealed weapons on campus.
Strongly

Approve Approve

13. Which of the previous proposals in questions $7-12$ presents the biggest amount of risk?

Allowing multiple CCW licensed teachers to carry concealed weapons on campus. Allowing a single $\mathrm{CCW}$ licensed teacher to carry a concealed weapon on campus.

Allowing multiple $\mathrm{CCW}$ licensed administrators to carry concealed weapons on campus.

Allowing a single CCW licensed administrator to carry a concealed weapon on campus.

Allowing CCW licensed (retired) police officers to serve as substitute teachers and carry concealed weapons on campus. 
14. Please explain the reasoning for your selection on question 13.

15. Which of the previous proposals in questions 7-12 presents the least amount of risk?

Allowing multiple CCW (Carry a Concealed Weapon) licensed teachers to carry concealed weapons on campus.

Allowing a single $\mathrm{CCW}$ licensed teacher to carry a concealed weapon on campus.

Allowing multiple CCW licensed administrators to carry concealed weapons on campus.

Allowing a single CCW licensed administrator to carry a concealed weapon on campus.

Allowing CCW licensed (retired) police officers to serve as substitute teachers and carry concealed weapons on campus.

16. Please explain the reasoning for your selection on question 15.

17. Which of the previous proposals in questions 7-11 would you most likely support as a means to stop an active shooter, if any?

Allowing multiple CCW licensed teachers to carry concealed weapons on campus. Allowing a single $\mathrm{CCW}$ licensed teacher to carry a concealed weapon on campus. Allowing multiple $\mathrm{CCW}$ licensed administrators to carry concealed weapons on campus.

Allowing a single $\mathrm{CCW}$ licensed administrator to carry a concealed weapon on campus.

Allowing CCW licensed (retired) police officers to serve as substitute teachers and carry concealed weapons on campus.

None of the Above.

18. Please explain the reasoning for your selection on question 17. 
The next section refers to a hypothetical situation in which you are serving on a committee (appointed by the Board of Education) to develop a new policy specifically allowing teachers to carry concealed weapons on campus. Please respond as honestly and completely as possible.

19. What specific concerns, if any, would you raise about allowing teachers to carry a concealed weapon on campus?

20. What safeguards would need to be in place before allowing teachers to carry a concealed weapon on campus?

21. What specific considerations should be given for your school that may be different from other schools regarding this policy?

22. Would you be willing to carry a concealed weapon on campus as a means to stop an active shooter?

$\square$ Yes

No

$\square$ Unsure 
23. In your opinion, what would be the best way for your school to respond to an active shooter?

Last are some demographic questions that will be used for classification purposes only.

24. How many years have you worked as a school employee (total)?
$0-10$
$11-20$
$21+$
Prefer not to respond

25. Are you a classified, certified, or administrative employee?
Classified
Certified
Administrative
$\square$ Prefer not to respond

26. What is your gender?
Female
Male
Prefer not to respond

27. Is there anything that you would like to add for us to think about?

THANK YOU FOR COMPLETING THIS QUESTIONNAIRE! PLEASE RETURN YOUR RESPONSES IN THE ORIGINAL ENVELOPE AND IF YOU WOULD LIKE TO BE ENTERED INTO THE GIFT CARD DRAWING FILL OUT THE ENCLOSED CARD AND RETURN IT IN THE ENCLOSED SMALL ENVELOPE. IN ORDER TO PROTECT ANONYMITY, PLEASE DO NOT WRITE YOUR NAME ON THIS QUESTIONNAIRE OR EITHER ENVELOPE. 


\section{Appendix B \\ Randomized Hypothesis Testing for a Difference in Means}

Question 2: My school is a safe place to work.

Classified v. Certified:
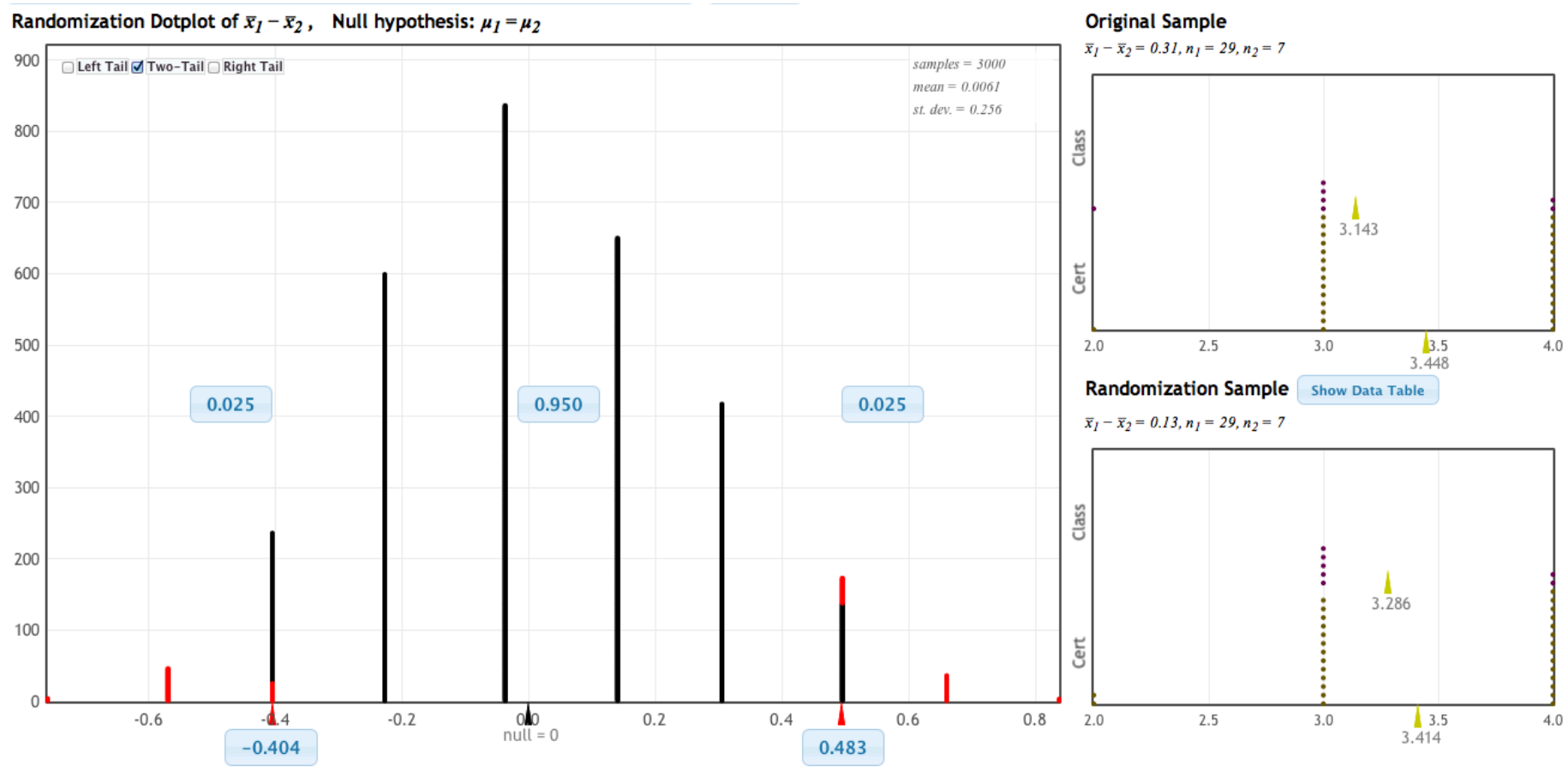

$\bar{x}_{1}-\bar{x}_{2}=0.13, n_{1}=29, n_{2}=7$

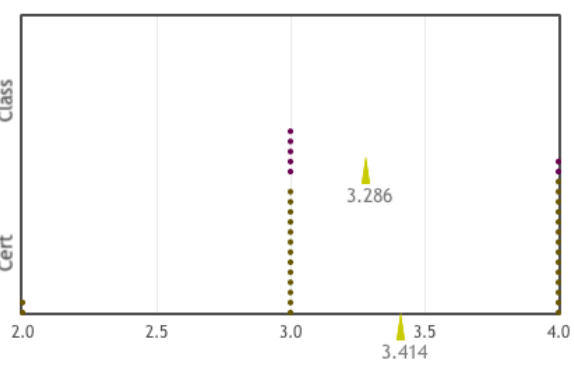

Male v. Female:

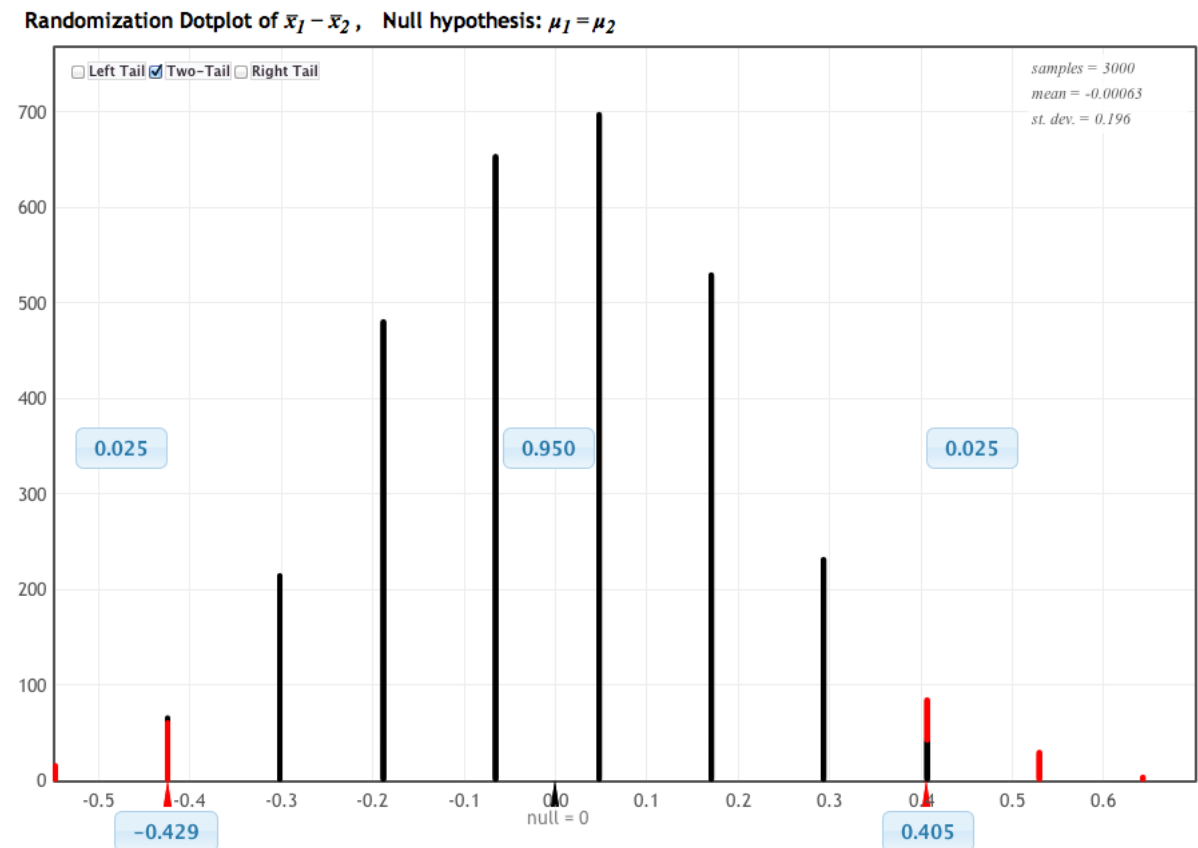

Original Sample

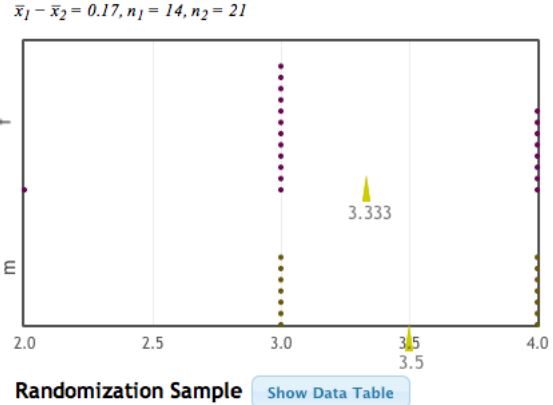

Randomization Sample Show Data Table

$\bar{x}_{1}-\bar{x}_{2}=-0.19, n_{1}=14, n_{2}=21$

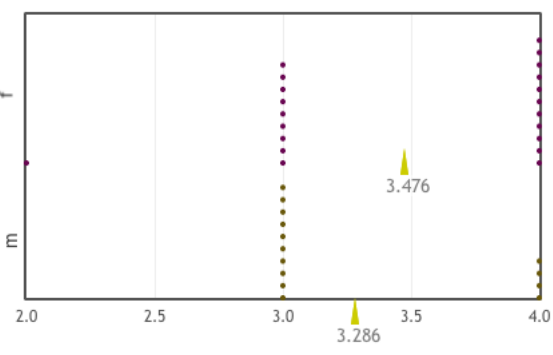


Question 3: I feel protected from any student physically harming me while at school. Classified v. Certified:

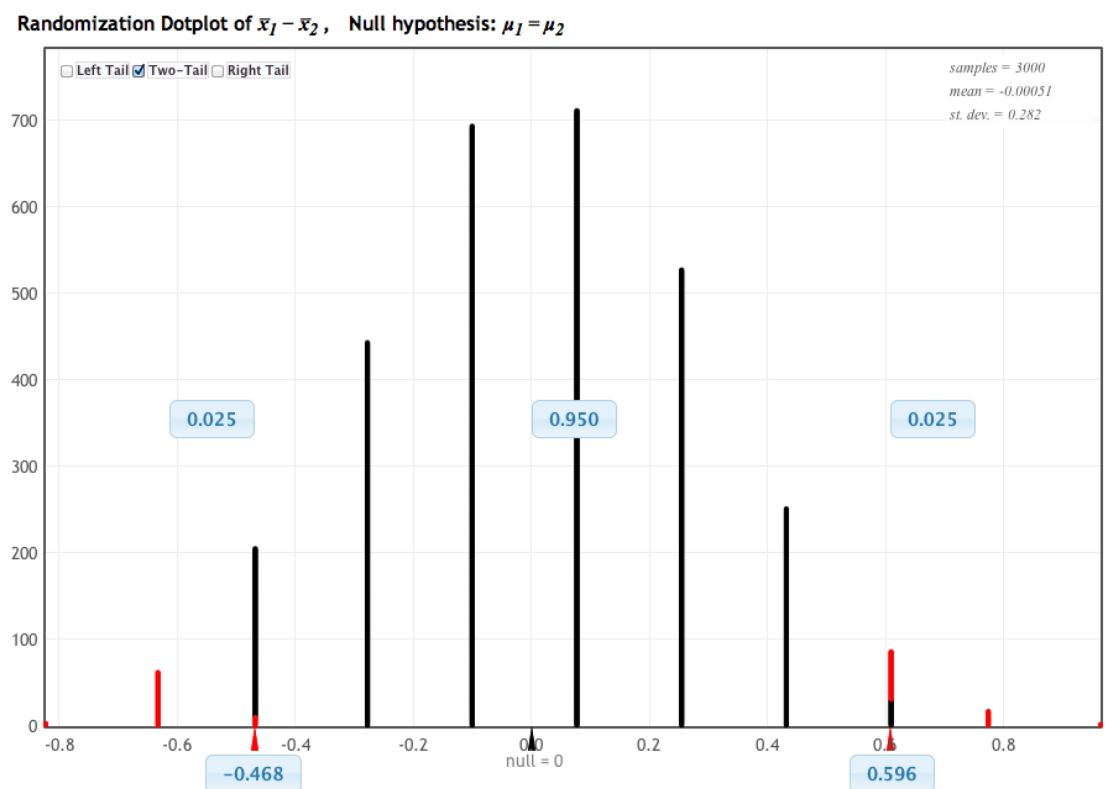

Original Sample

$\bar{x}_{1}-\bar{x}_{2}=0.42, n_{1}=29, n_{2}=7$

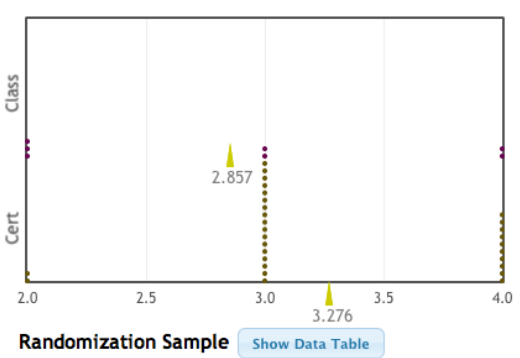

$\bar{x}_{1}-\bar{x}_{2}=0.06, n_{1}=29, n_{2}=$

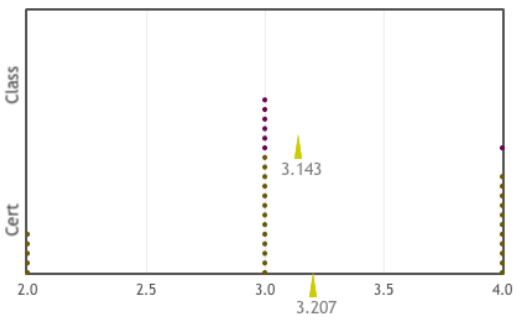

Male v. Female:

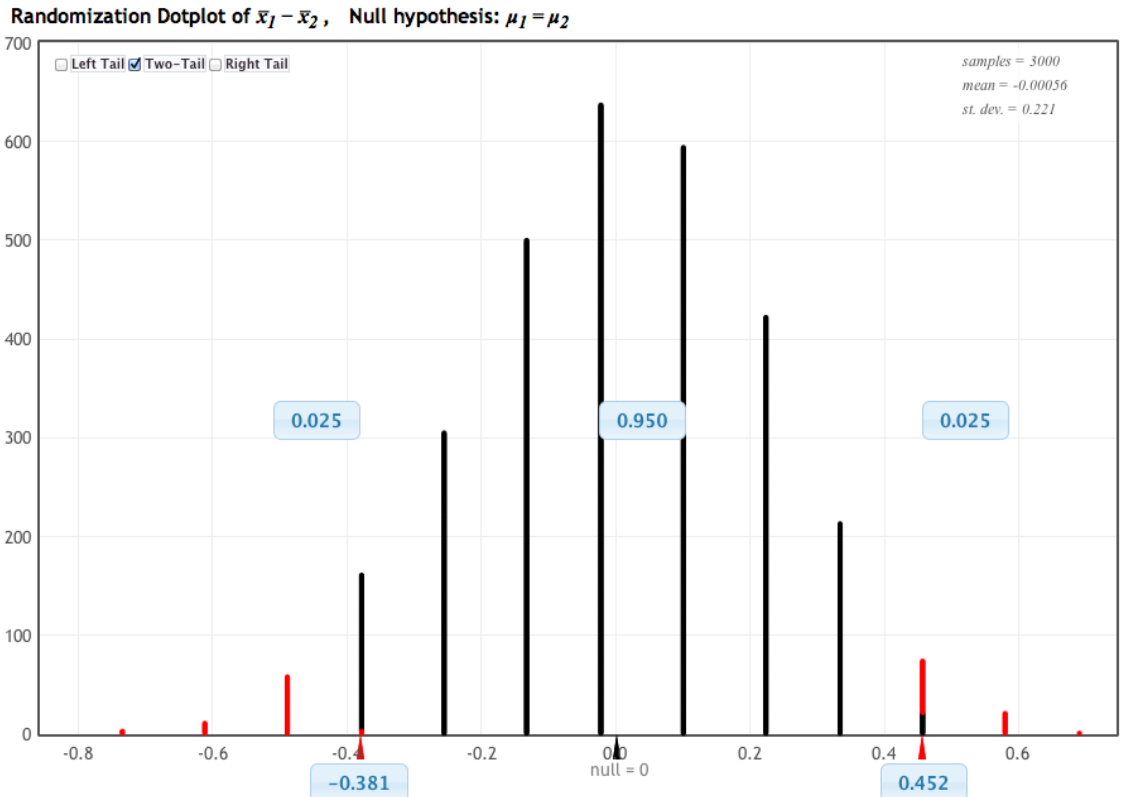

Original Sample

$\bar{x}_{I}-\bar{x}_{2}=-0.02, n_{I}=14, n_{2}=21$

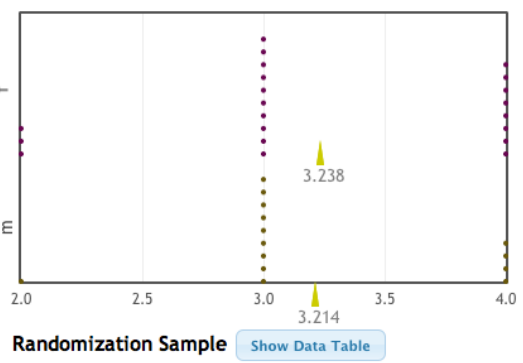

$\bar{x}_{1}-\bar{x}_{2}=0.1, n_{1}=14, n_{2}=21$

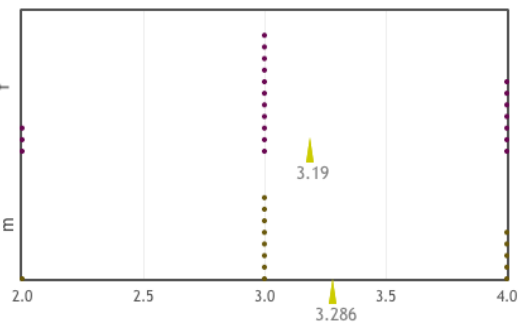


Question 4: I feel protected from any outsider (non-student) physically harming me while at school.

Classified v. Certified:

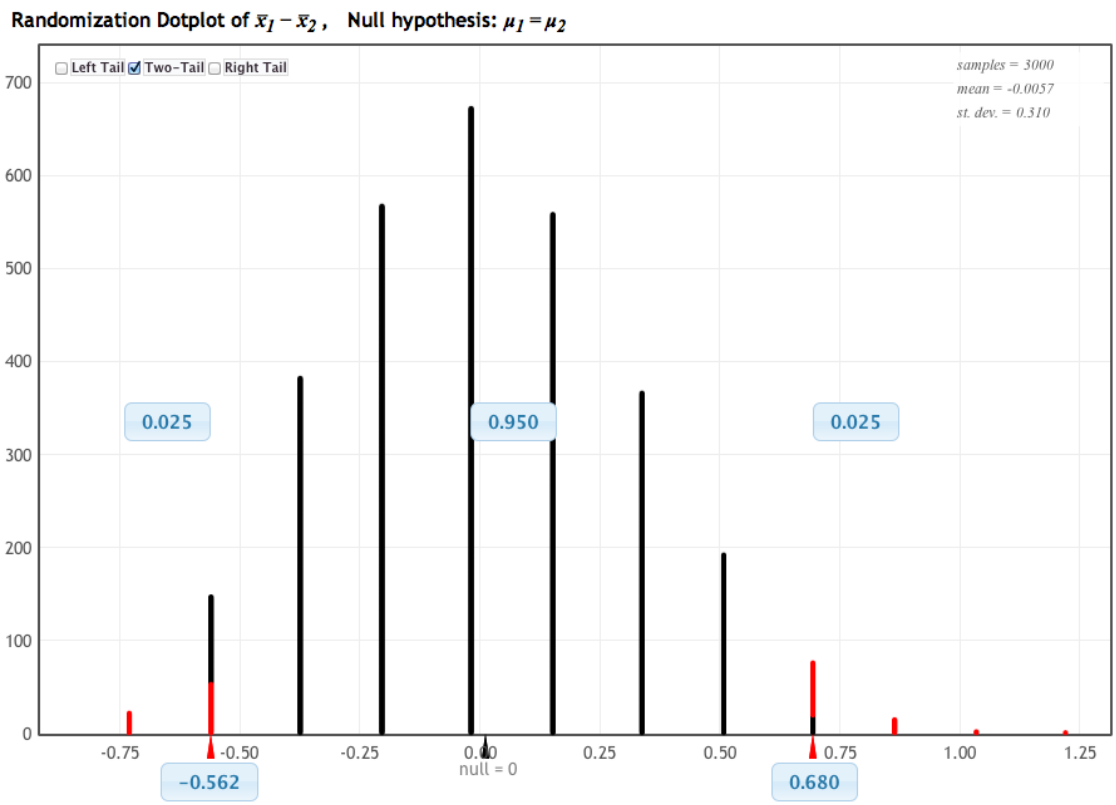

Original Sample

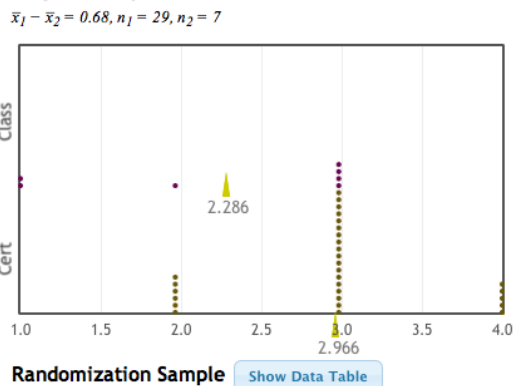

Randomization Sample Show Data Table

$\bar{x}_{1}-\bar{x}_{2}=-0.21, n_{1}=29, n_{2}=7$

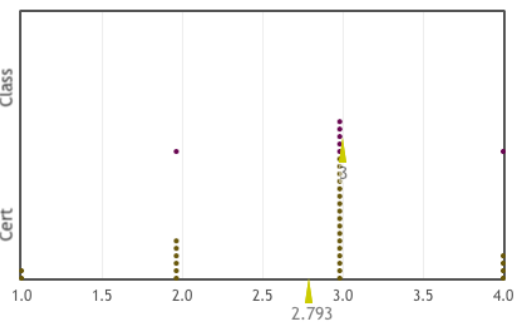

Male v. Female:

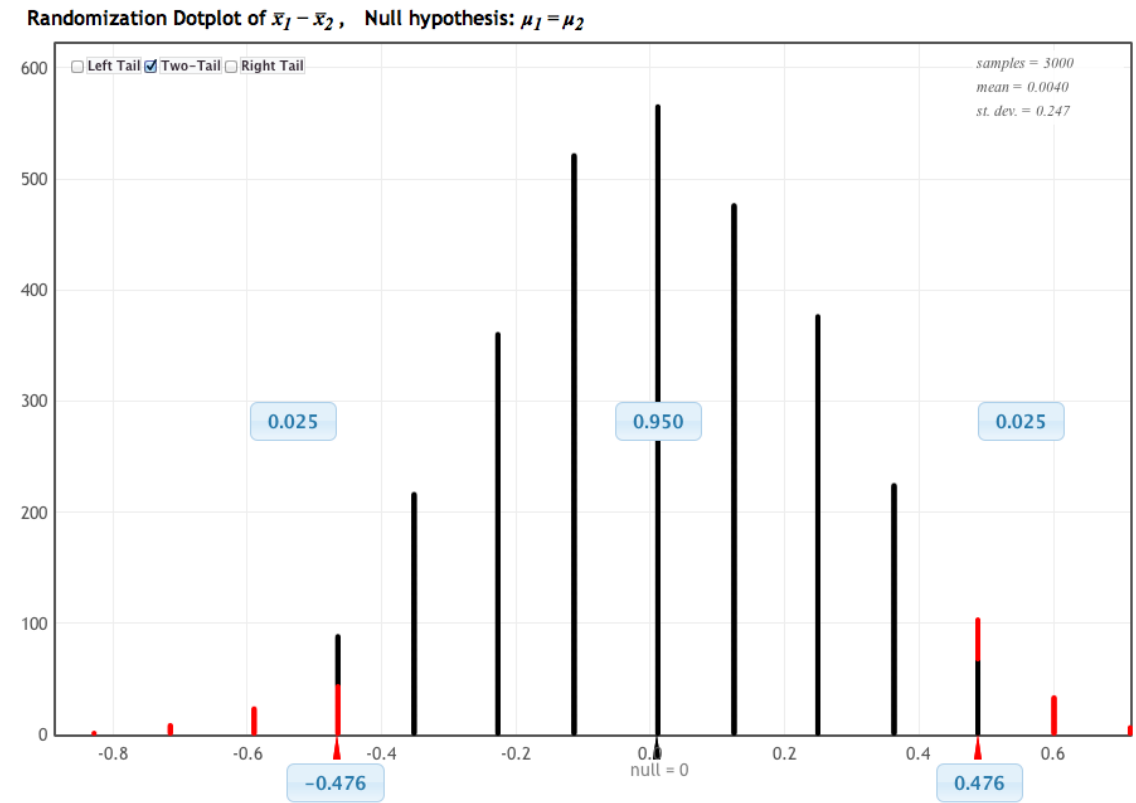

Original Sample

$\bar{x}_{1}-\bar{x}_{2}=0.12, n_{1}=14, n_{2}=21$

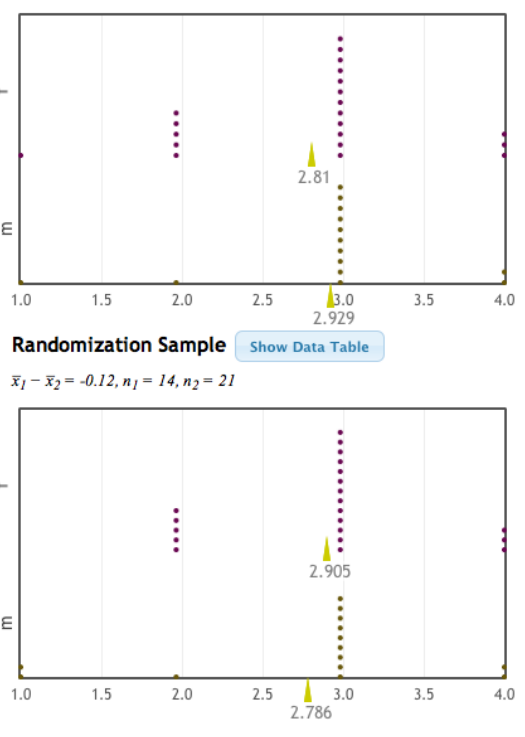


Question 5: I feel that my school has sufficient procedures in place to protect others and myself in the event of an active shooter.

Classified v. Certified:
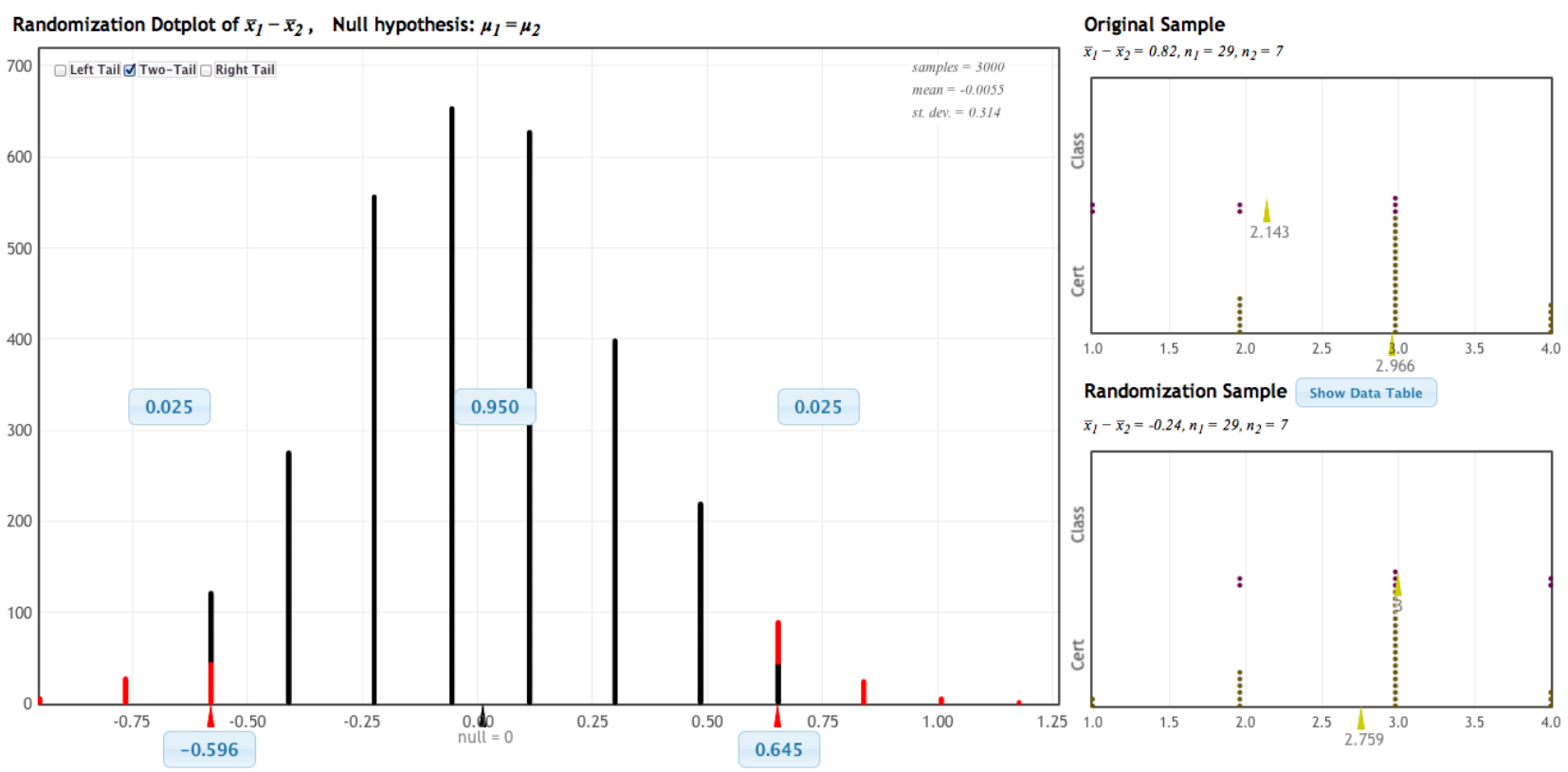

Male v. Female:
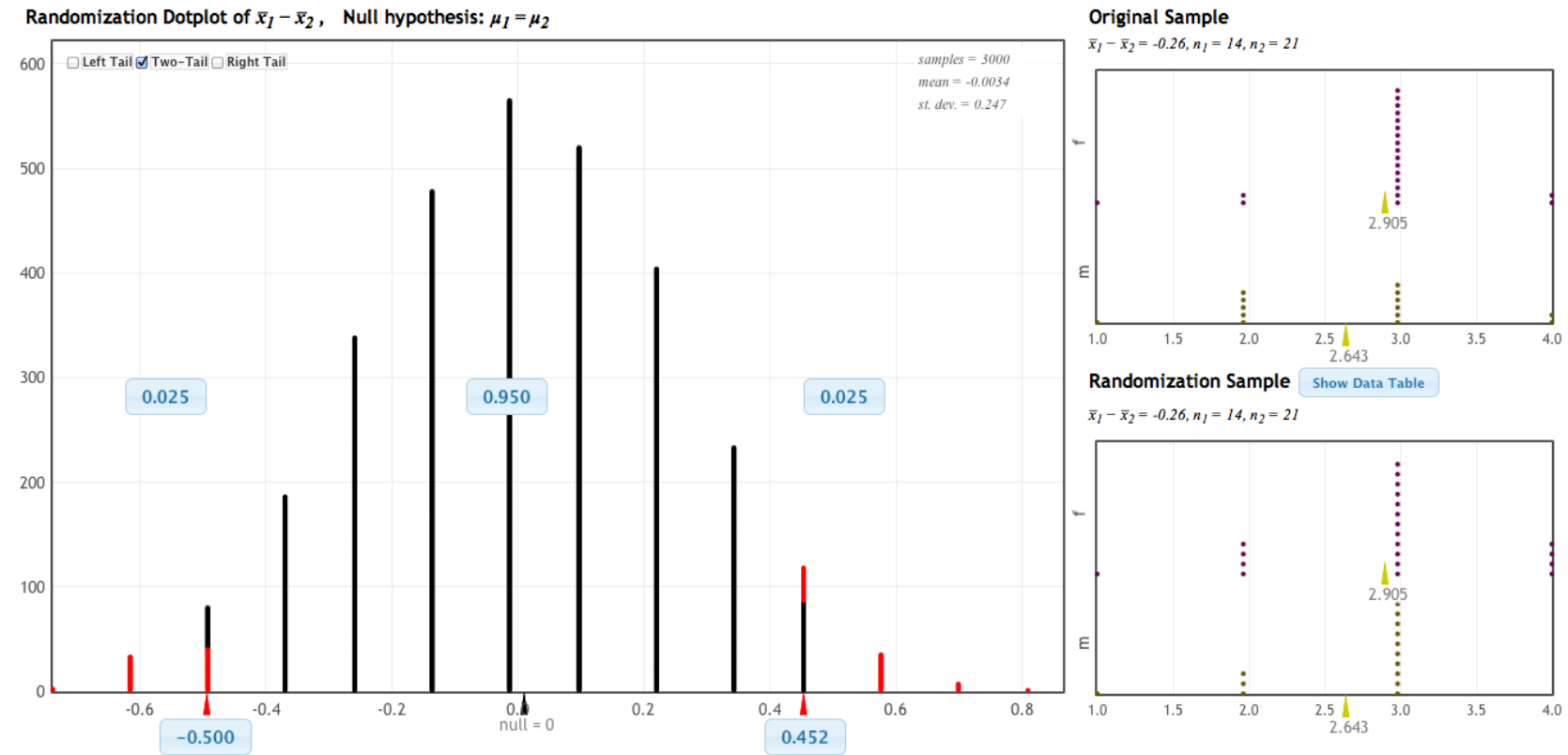
Question 7: Allowing multiple, Board approved, CCW (Carry a Concealed Weapon) licensed teachers to carry concealed weapons on campus.

Classified v. Certified:
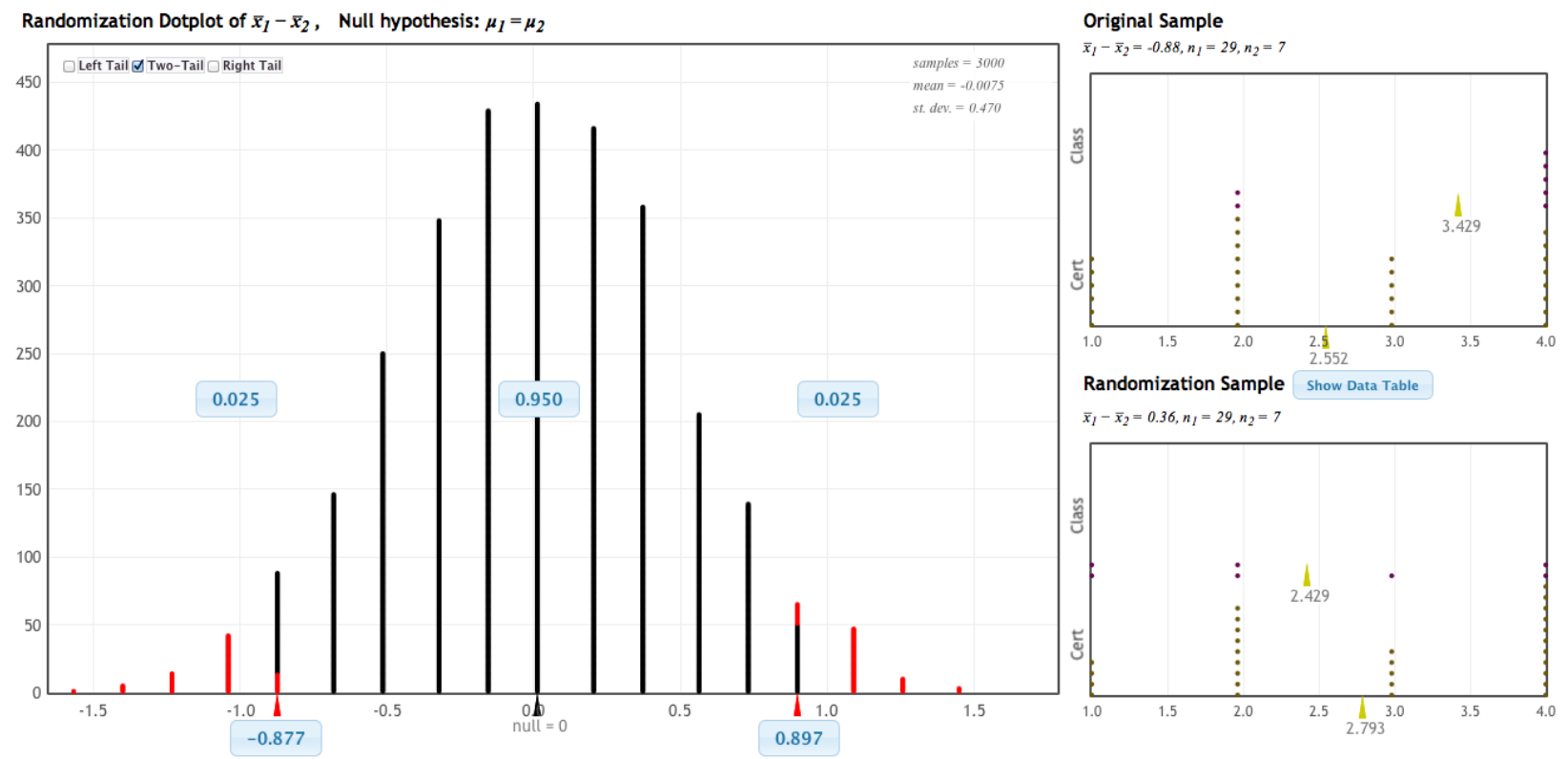

Male v. Female:
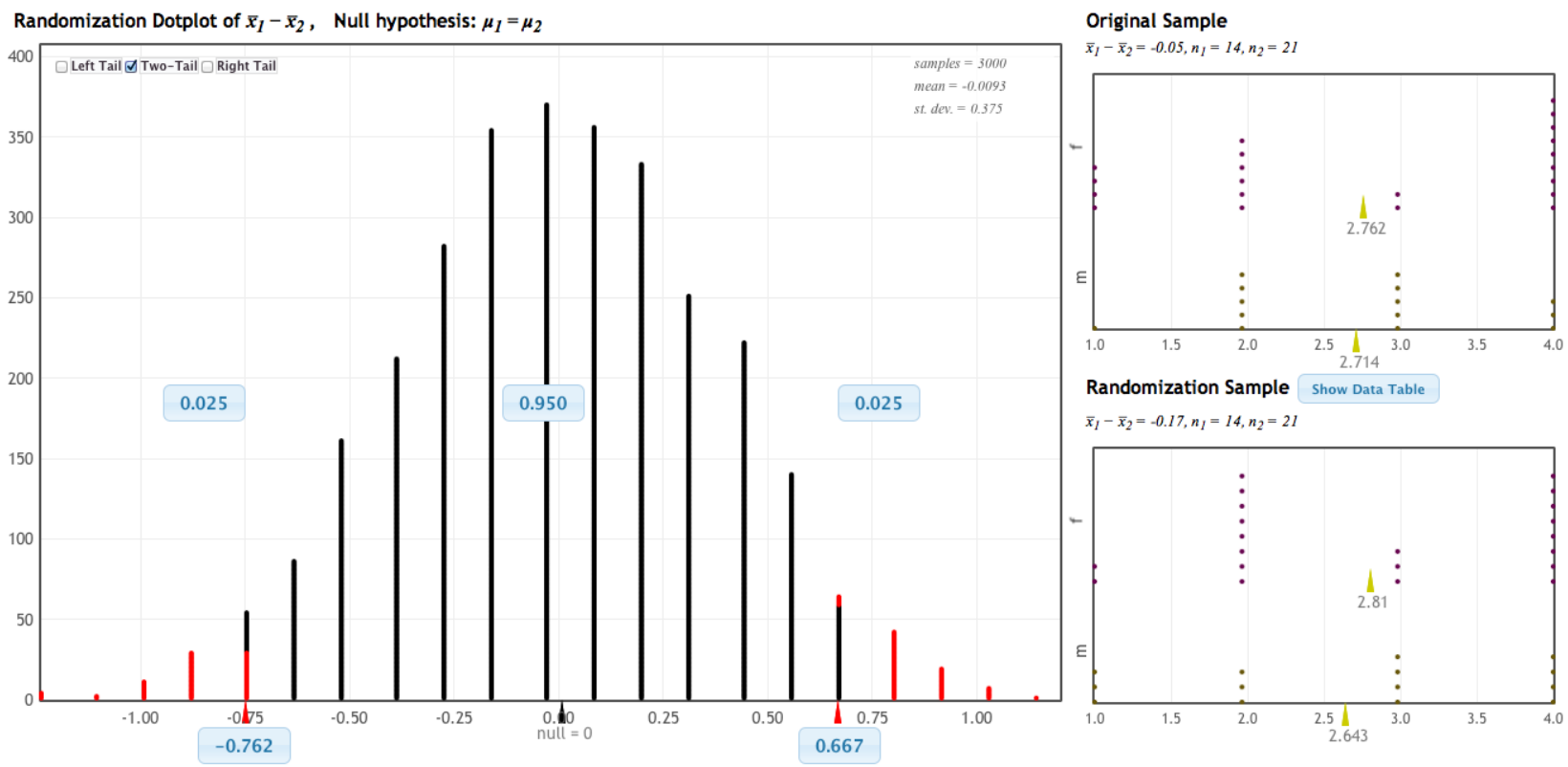
Question 8: Allowing a single, Board approved, CCW licensed teacher to carry a concealed weapon on campus.

Classified v. Certified:
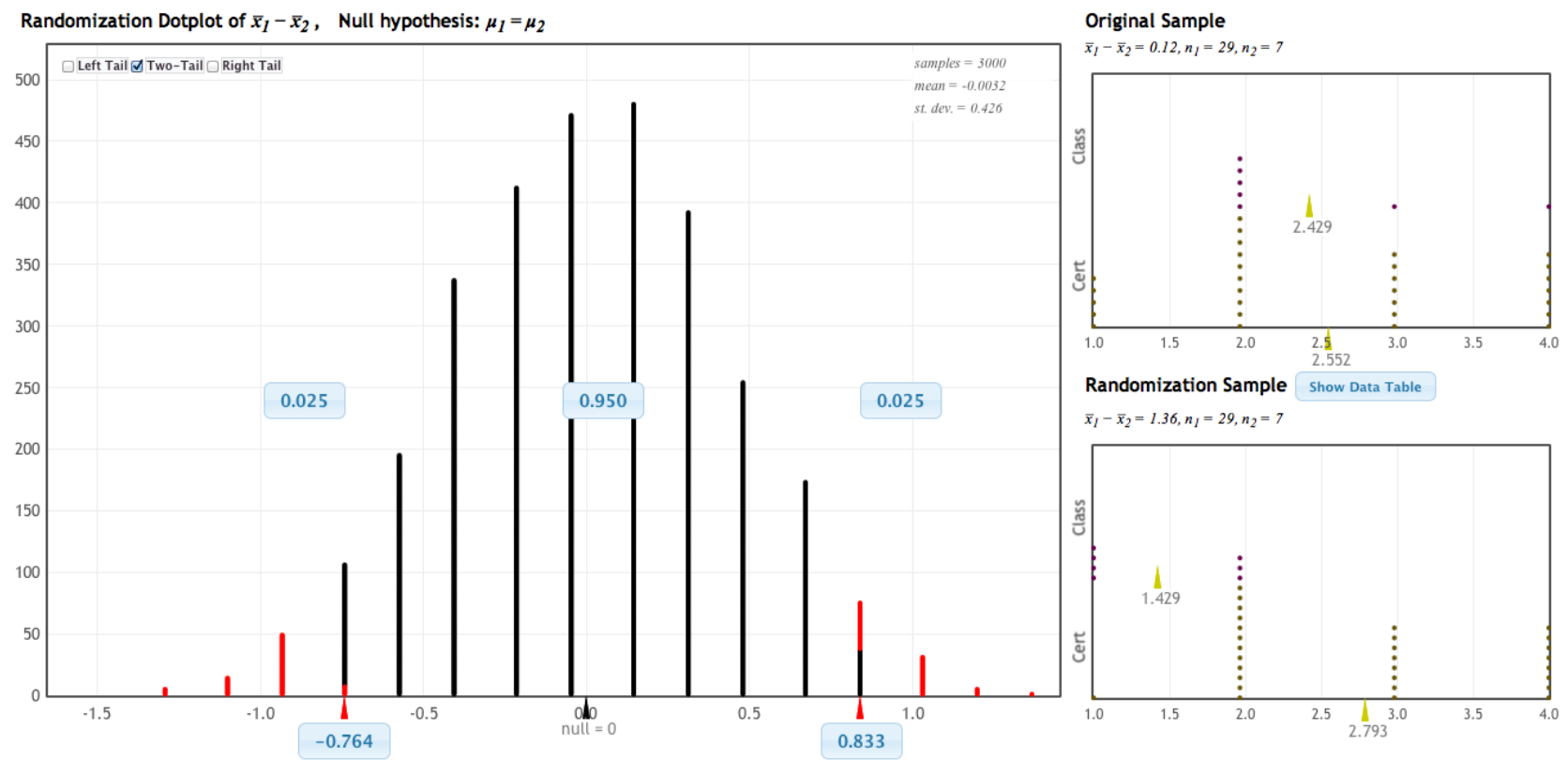

Male v. Female:
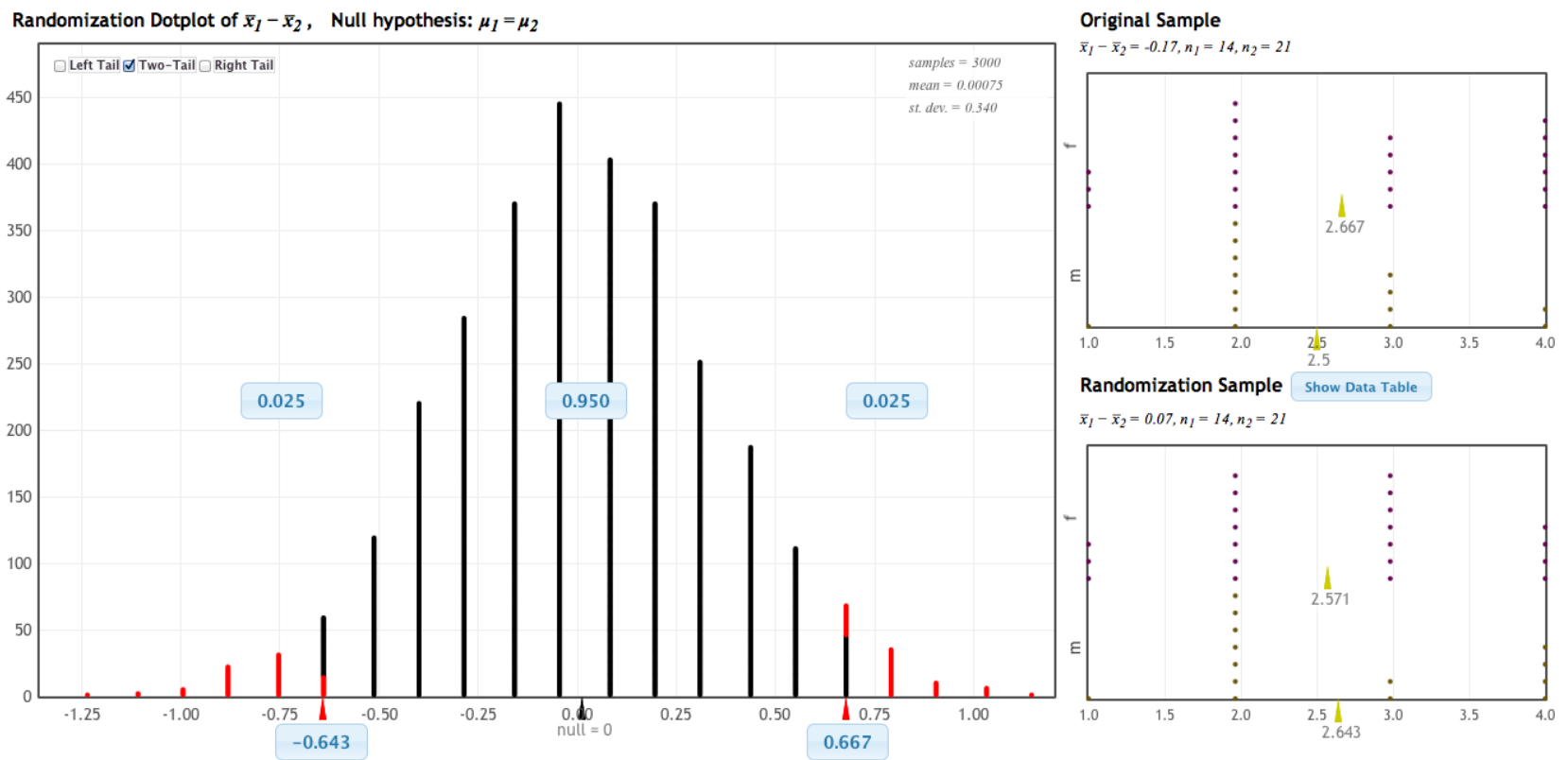
Question 9: Allowing multiple, Board approved, CCW licensed administrators to carry concealed weapons on campus.

Classified v. Certified:
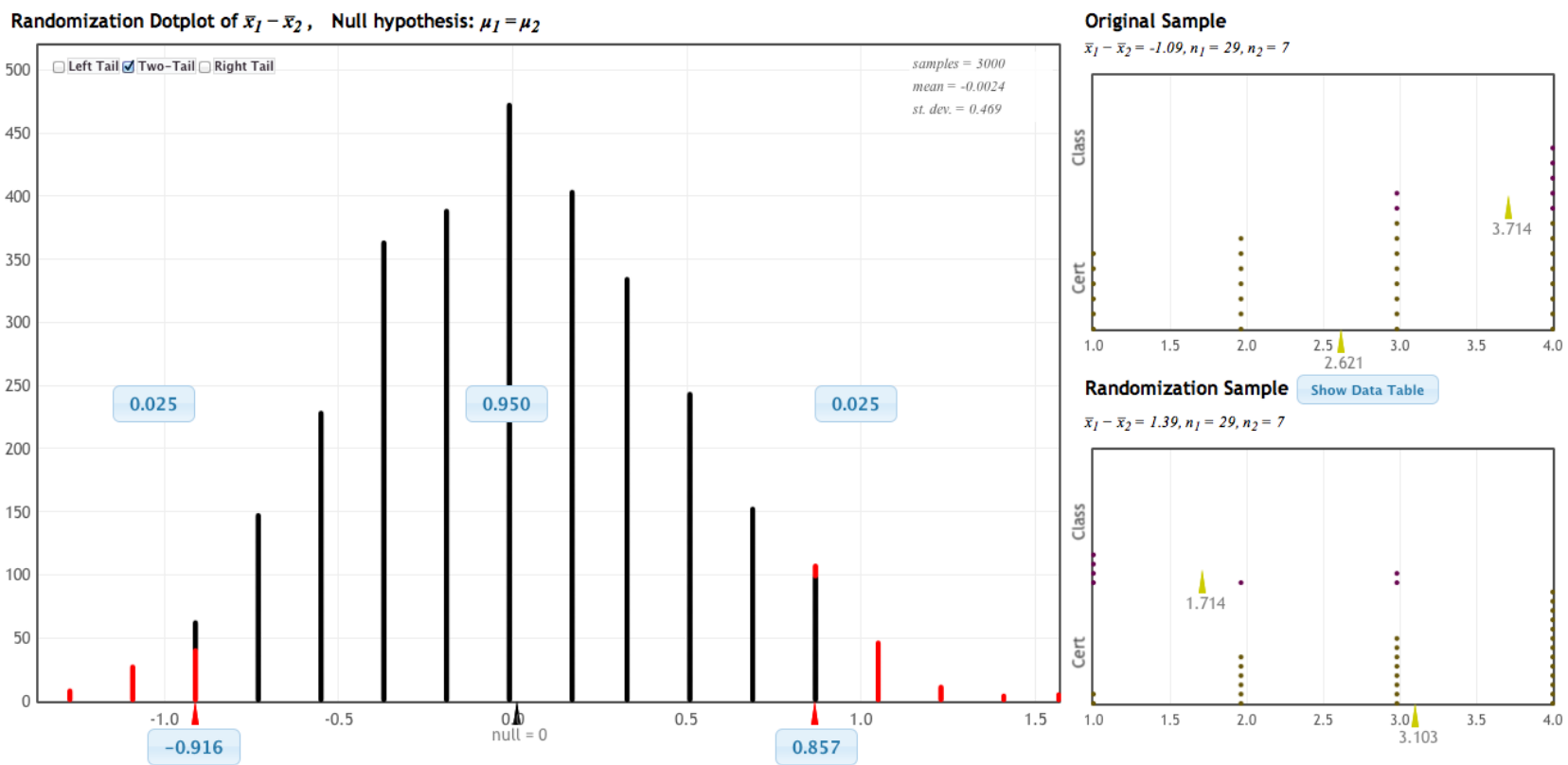

Male v. Female:
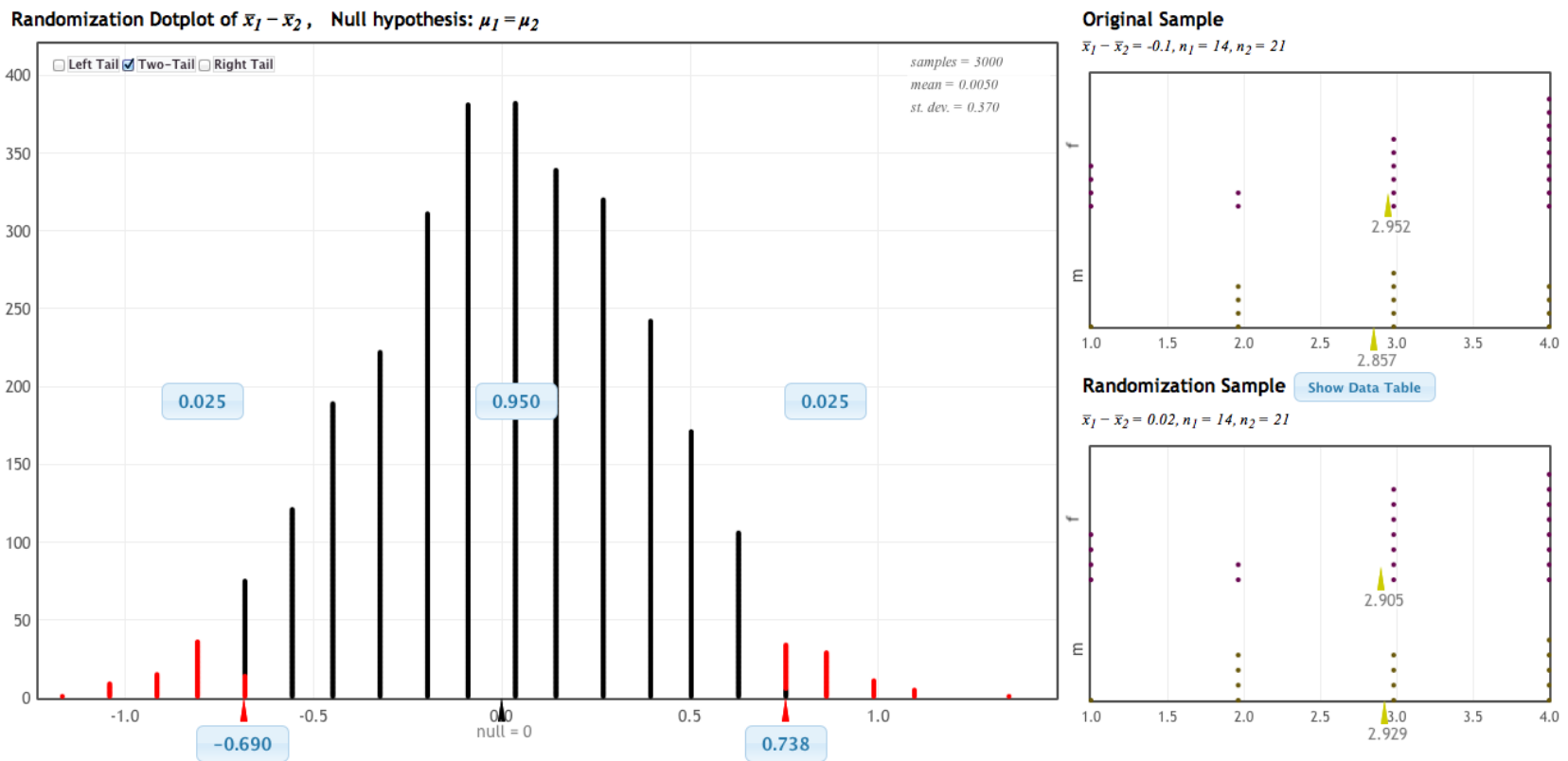
Question 10: Allowing a single, Board approved, CCW licensed administrator to carry a concealed weapon on campus.

Classified v. Certified:
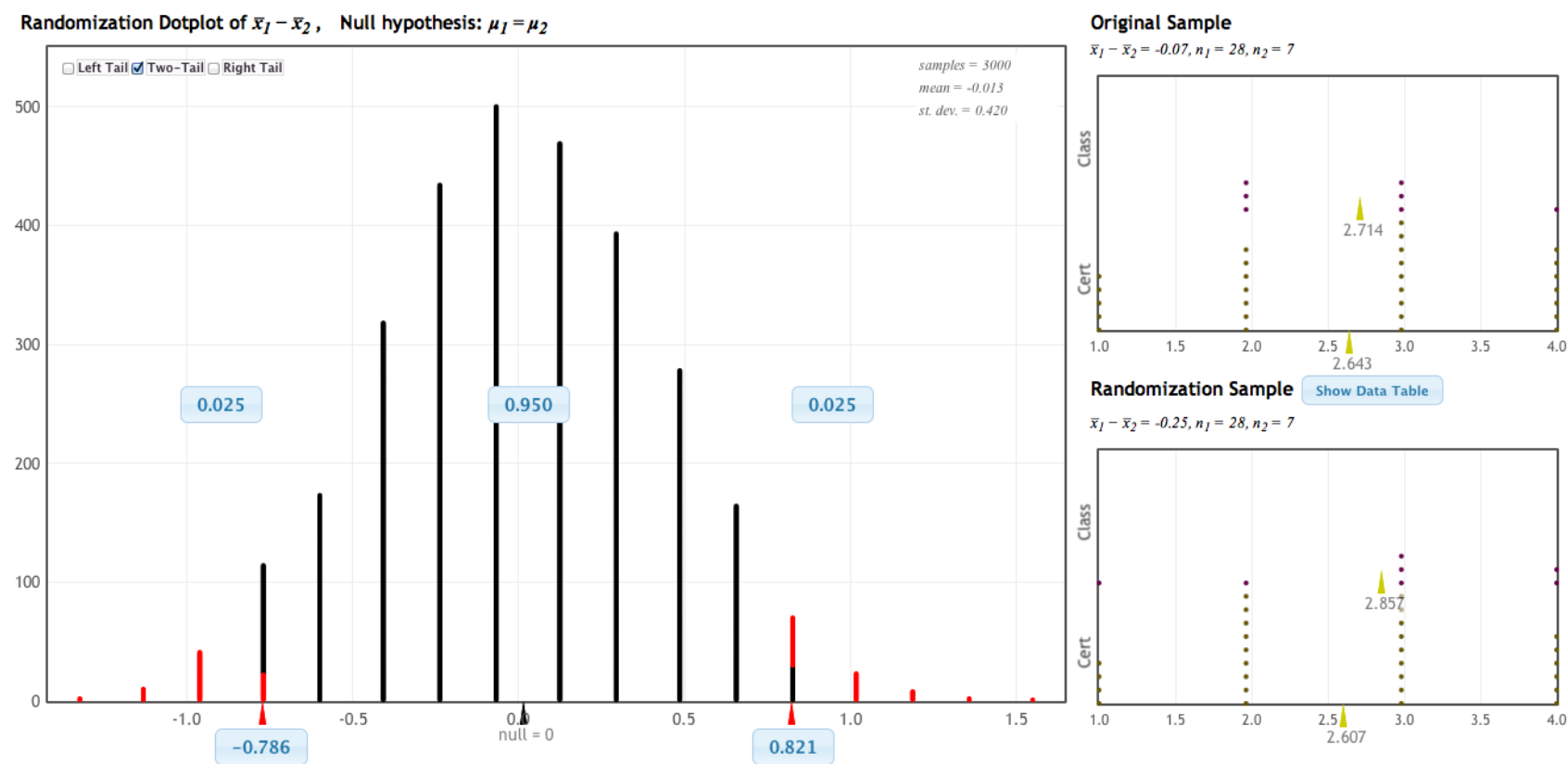

Randomization Sample Show Data Table

$\bar{x}_{1}-\bar{x}_{2}=-0.25, n_{1}=28, n_{2}=7$

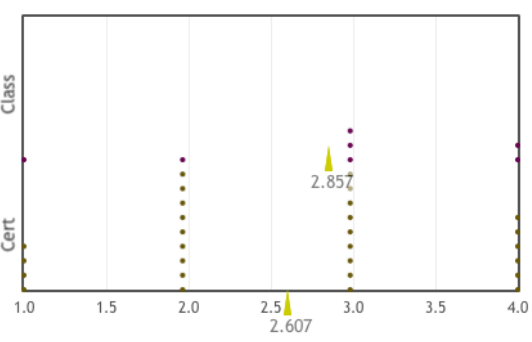

Male v. Female:
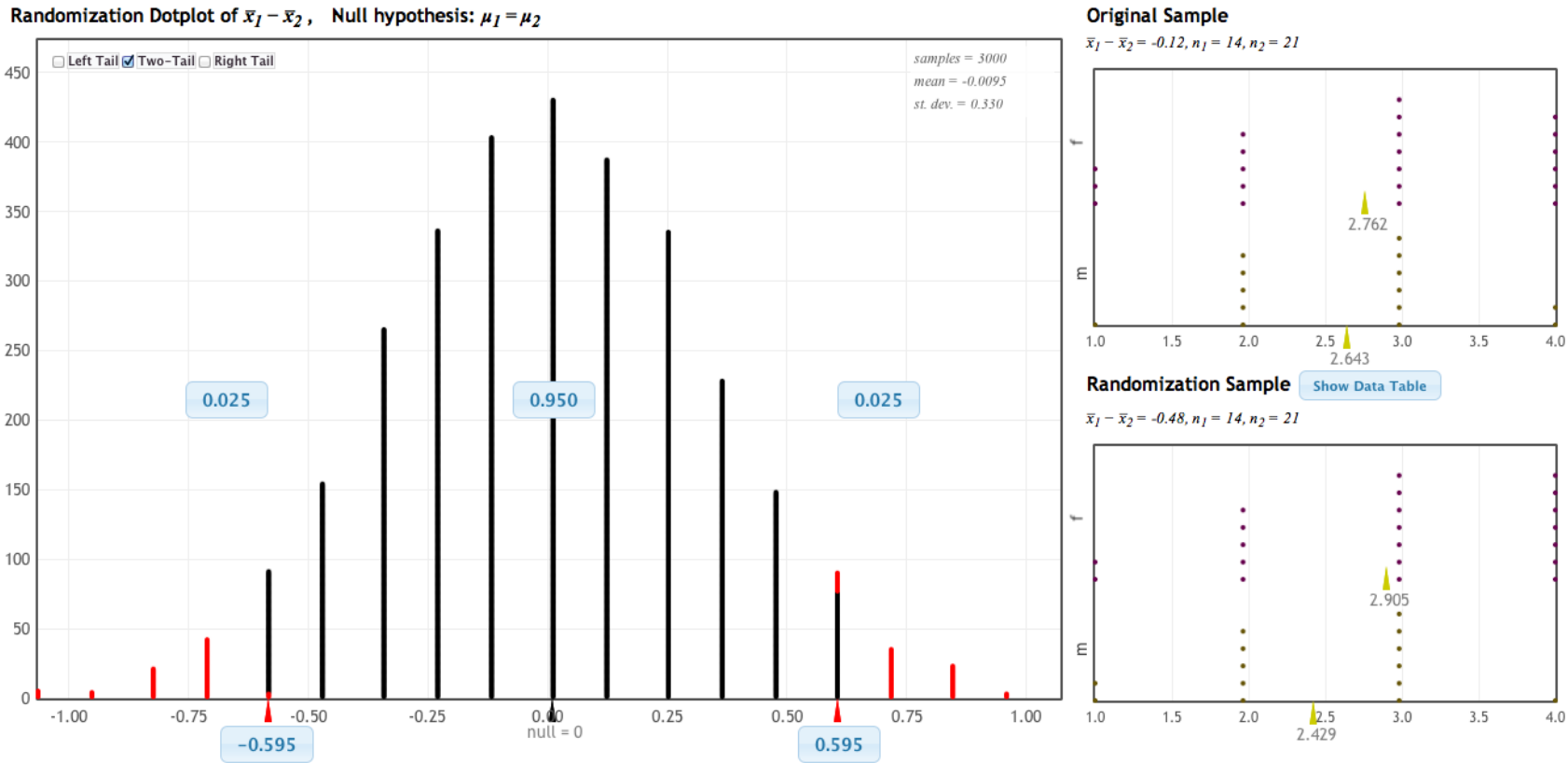
Question 11: Allowing Board approved, CCW licensed (retired) police officers to serve as substitute teachers and carry a concealed weapon on campus.

Classified v. Certified:
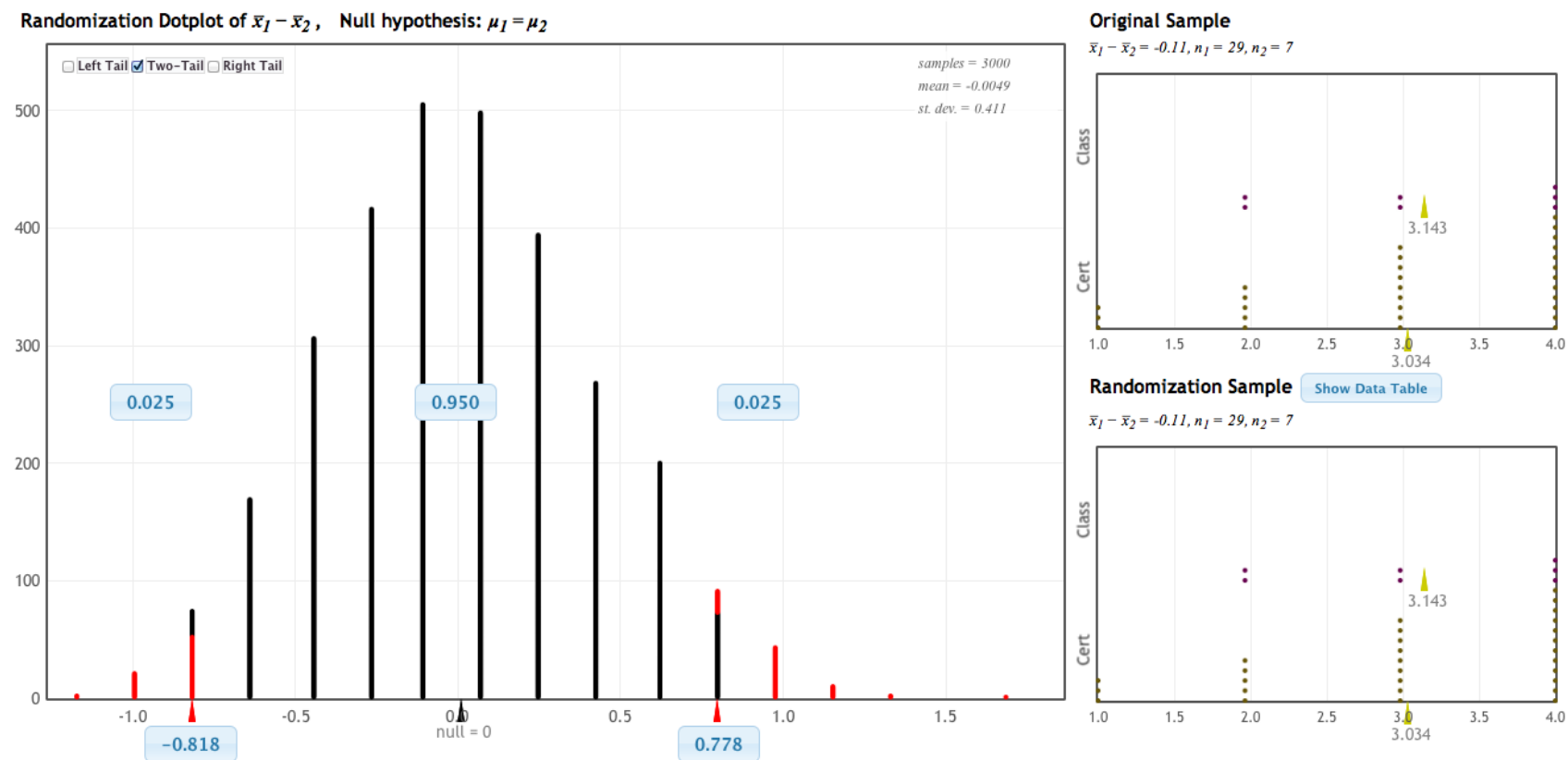

Male v. Female:

Randomization Dotplot of $\bar{x}_{1}-\bar{x}_{2}$, Null hypothesis: $\mu_{1}=\mu_{2}$

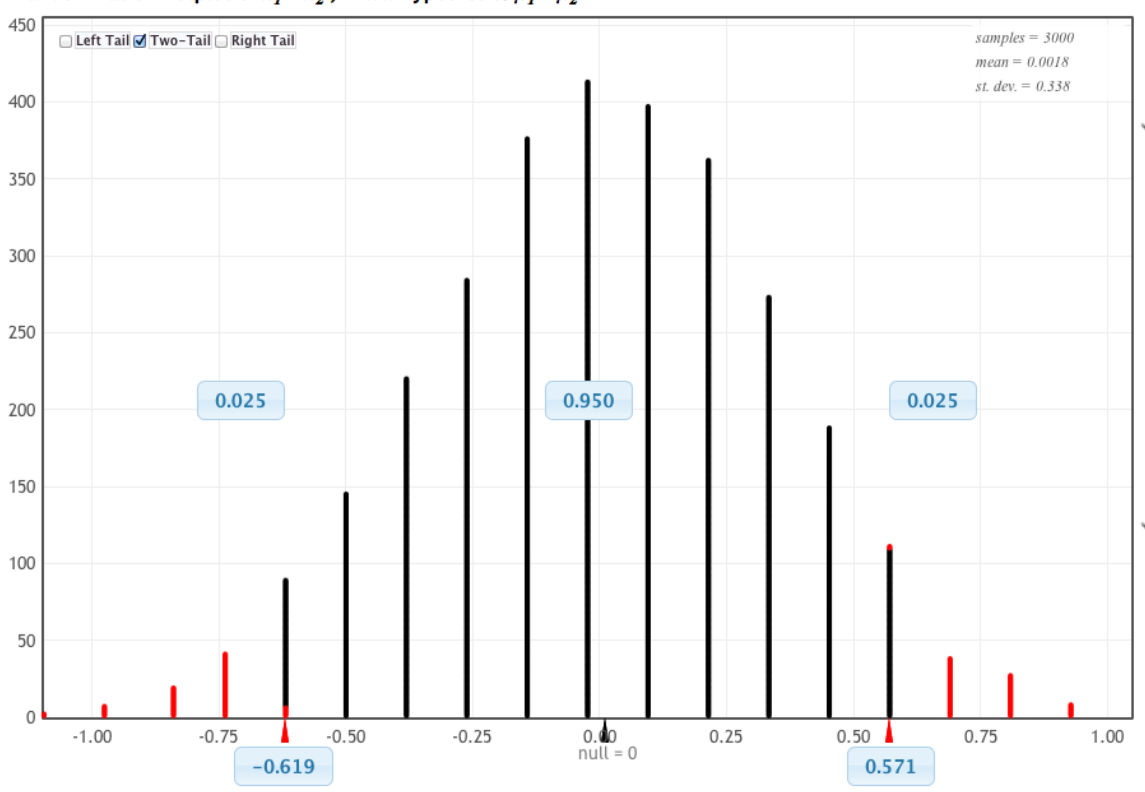

Original Sample $\bar{x}_{1}-\bar{x}_{2}=-0.14, n_{1}=14, n_{2}=21$

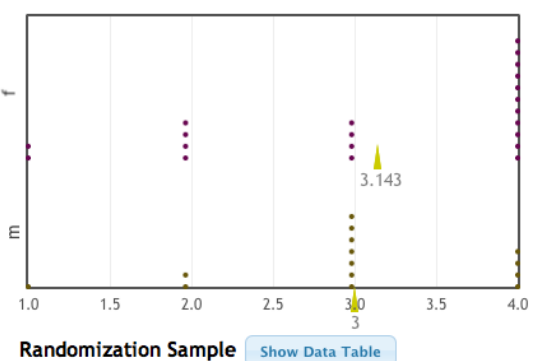

Randomization Sample Show Data Table

$\bar{x}_{1}-\bar{x}_{2}=0.33, n_{l}=14, n_{2}=2 l$

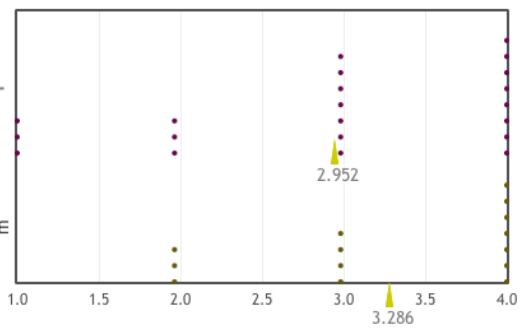


Question 12: Allowing Board approved, CCW licensed security officers to carry concealed weapons on campus.

Classified v. Certified:
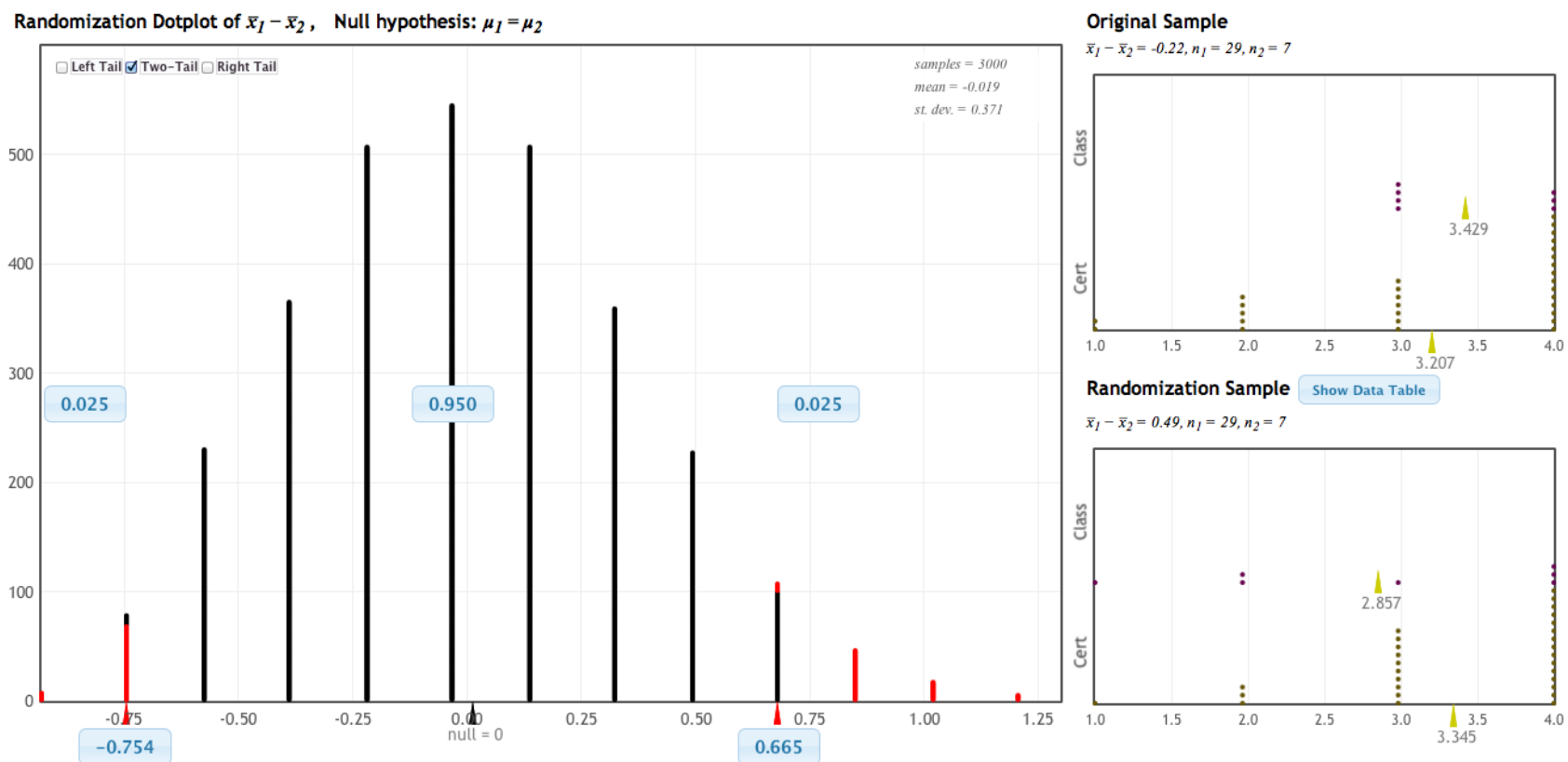

Male v. Female:

Randomization Dotplot of $\bar{x}_{1}-\bar{x}_{2}, \quad$ Null hypothesis: $\mu_{1}=\mu_{2}$

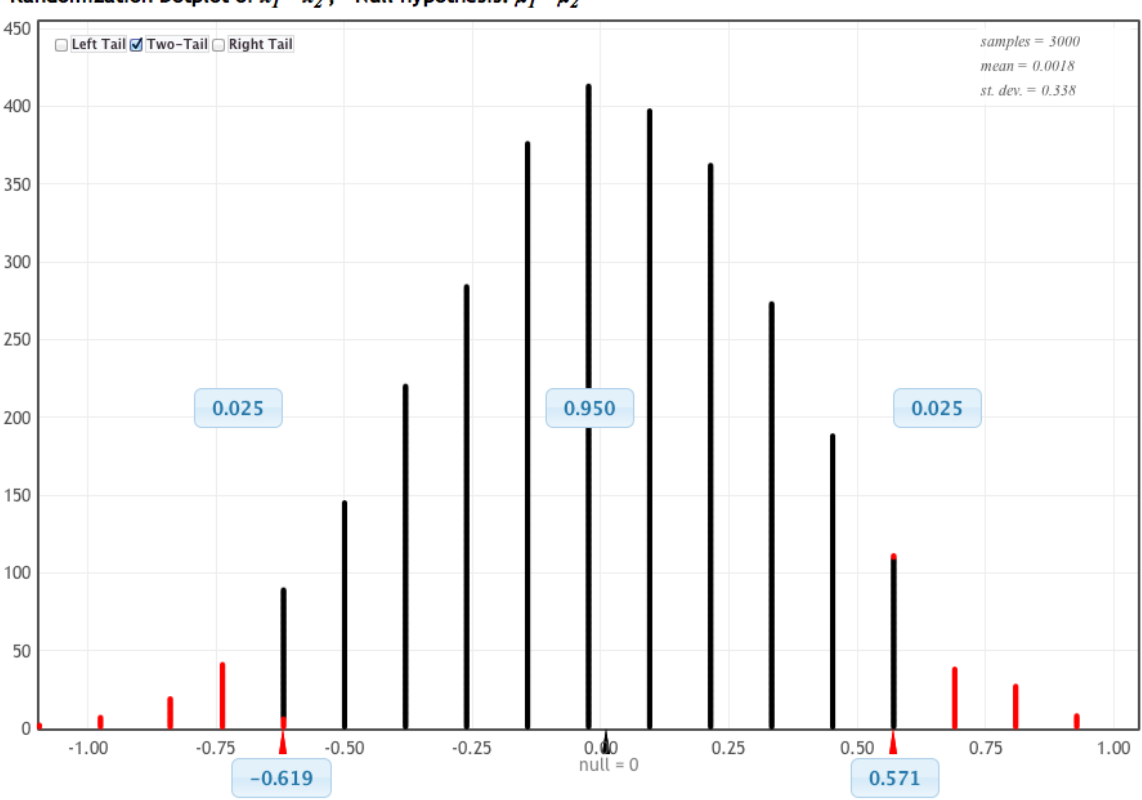

Original Sample

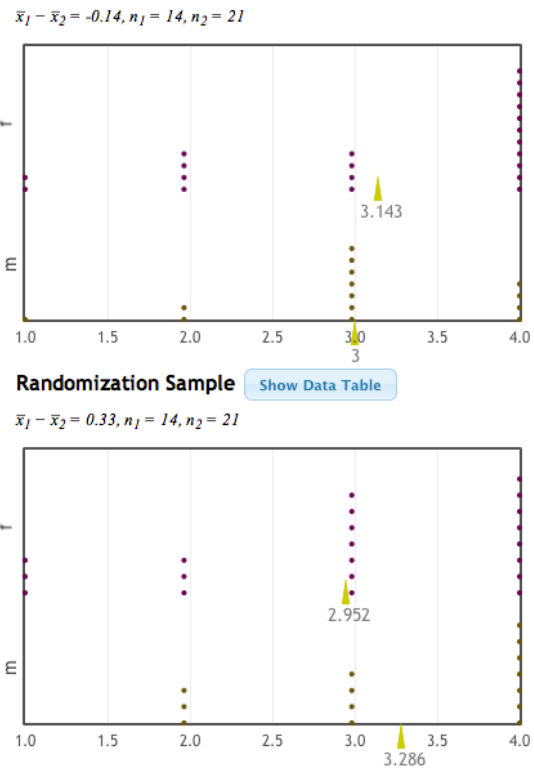

